\title{
Mechanism of an asphaltene inhibitor in different depositing environments: Influence of colloid stability
}

Sophie Campen ${ }^{1}$, Saul J. Moorhouse ${ }^{2}$ and Janet S. S. Wong ${ }^{1 *}$

'Department of Mechanical Engineering, Imperial College London, UK SW7 2AZ

${ }^{2}$ BP Exploration Operating Company Limited, Chertsey Road, Sunbury-on-Thames, Middlesex, UK TW16 7LN

*Corresponding author. Telephone: +44 (0)20 7594 8991. E-mail: j.wong@imperial.ac.uk

\begin{abstract}
Additives are used to reduce unwanted carbonaceous deposits of asphaltenes on surfaces during petroleum production from natural oil and gas reservoirs. The working mechanism of formulated additive packages can be multifaceted. Additives may be effective in the bulk fluid by preventing asphaltenes aggregation, as well as at the surface by preventing asphaltenes adhesion. In this paper, we investigate the numerous different mechanisms by which an asphaltene inhibitor can interfere with the formation of carbonaceous deposits using a combination of techniques including dynamic light scattering to determine particle size distribution, quartz crystal microbalance with dissipation monitoring to examine deposition behaviour and atomic force microscopy to probe deposit morphology. The tested inhibitor prevents deposition of asphaltenes in toluene, where asphaltenes exist as a stable colloidal dispersion of nanoaggregates, by forming barrier-type films that inhibit asphaltenes adhesion and displacing adsorbed thin films of asphaltenes. However, inhibitor performance in heptane-toluene, where asphaltenes are destabilised, depends on the degree of destabilisation. At low heptane volume fraction, inhibitor slows the rate of deposition and deposition rate decreases with increasing inhibitor concentration. However, at high heptane volume fraction, inhibitor can increase the deposition rate, particularly when used in high concentration. At high heptane volume fraction, inhibitor addition alters the morphology of the deposit from that consisting of large flocculent aggregates to that consisting of smaller, submicrometer aggregates. This is consistent with the finding that inhibitor acts as an anti-agglomerant and prevents the formation of large aggregates in the bulk liquid. This paper shows that the impact of inhibitor addition depends on the environmental conditions encountered and the degree of destabilisation of the asphaltenes. Where inhibitor addition alters the nature of depositing species from large flocculent aggregates to smaller submicrometer aggregates, an increase in deposition rate may be observed.
\end{abstract}

\section{Keywords}

asphaltenes, fouling, inhibitor, remediation, colloid, QCM-D 


\section{Introduction}

Asphaltenes are the densest, most polar fraction of crude oil and consist of an array of different molecular structures that typically contain polycyclic aromatic hydrocarbons (Adams, 2014; Ruizmorales and Mullins, 2007; Schuler et al., 2015). During production of crude oil, changing environmental conditions act to destabilise asphaltenes, leading to increased intermolecular selfassociation, aggregation, precipitation, flocculation, and surface deposition (Kurup et al., 2011; Mullins, 2011). Surface deposition of asphaltenes can be problematic as it decreases the efficiency of petroleum production and processing, costing the oil and gas industry billions of US dollars per year (Creek, 2005; Rogel et al., 2010).

Several strategies are currently employed to prevent asphaltene deposition. These include the use of additives to delay / prevent the onset of asphaltene precipitation or disperse precipitated asphaltenes (Smith et al., 2008). Another method is the use of barriers, i.e. surface coatings. Coatings can alter the chemistry and morphology of the surface, thus altering both the propensity for adsorption and the nature of the fluid flow across the surface (Dudášová et al., 2008b, 2008a; Lin et al., 2016; Pradilla et al., 2016; Seyyedbagheri and Mirzayi, 2017; Sung et al., 2016). Coatings of organosilane selfassembled monolayers (SAMs) reduced asphaltene adsorption onto silicon substrates (TurgmanCohen et al., 2009a, 2009b). While covalently-bound polymer brush coatings altered the liquidsurface interfacial energy, preventing asphaltene adhesion (Higaki et al., 2014). Operational changes can also be implemented to alter the amount of deposit formation. For example, flow rate from the reservoir to the surface facilities and thereon can be controlled in upstream oil production and temperature can be controlled in refining (Hashmi et al., 2015; Kor and Kharrat, 2016; Mohammadi et al., 2016). Of the preventive measures, it is the use of additives such as asphaltene inhibitors that can be most readily implemented. Coating the surfaces of upstream sub-sea pipelines that are already in use would be a major operation and may not feasibly be undertaken due to logistics and cost. Operational changes are only possible within reason, since there may be other constraints on production.

Generally, some carbonaceous deposits formation is unavoidable. In such cases remedial methods are needed to remove deposited films. Solvent cleaning (e.g. with xylene or other aromatics) is used to dissolve deposits (Elochukwu and Mahmud, 2015; Mansoori, 2010). Additives (e.g. dispersants) and co-solvent can aid deposit removal (Darabi and Sepehrnoori, 2015; Madhi et al., 2018; Trbovich and King, 1991). Alternatively, de-asphalted oil may be reinjected to dissolve deposits (Jamaluddin and Nazarko, 1995). Deposits are also mechanically removed from oil pipes by a process referred to as 'pigging' (Alnaimi et al., 2016; Guo et al., 2005; Wylde, 2011). Informed control of the intervals between remedial cleaning is required for maximum efficiency. Intermittent remedial cleaning may be viewed as a preventative measure for catastrophic complete wellbore plugging (Leontaritis et al., 1994).

Asphaltene inhibitors are typically amphiphilic surfactant or dispersant-type molecules. Reported inhibitors include mono-substituted esters of glycerol (Breen, 2001), esters of sorbitan (Spans) 
(Breen, 2001), alkylamines (Subramanian et al., 2018b), alkylphenols (Chang and Fogler, 1994; Goual et al., 2014; Rogel and León, 2001; Wei et al., 2015), alkylbenzene sulfonates such as dodecylbenzyl sulfonic acid (Benayada and Rahmani, 1999; Chang and Fogler, 1994; Goual and Sedghi, 2015; León et al., 1999; Liu et al., 2015; Wei et al., 2015) and polymeric dispersants such as polyisobutylene succinimides (PIBS) (Breen, 2001; Hashmi et al., 2010; Hashmi and Firoozabadi, 2012; Manek and Sawhney, 1996; Marques et al., 2012; Wang et al., 2017). It has been theorised that resins, which are naturally occurring in crude oil, can stabilise asphaltenes (Acevedo et al., 1995; Kawanaka et al., 1989; Leontaritis and Mansoori, 1987; Pfeiffer and Saal, 1939; Porte et al., 2003; Soorghali et al., 2014), hence chemists may look to utilise these chemistries by finding synthetic analogues or by recycling / reintroducing natural resins (Khvostichenko and Andersen, 2010; Speight, 2004). Inhibitor performance depends on the individual chemistry of the asphaltene / crude oil (Ibrahim and Idem, 2004; Rogel, 2011; Smith et al., 2008; Wang et al., 2009) and the surface type (Al Sultan et al., 2018). Hence, selecting the right formulated asphaltene inhibitor package for the specific task in hand is of paramount importance.

It is generally considered that the main mechanism by which inhibitors reduce carbonaceous deposits formation is by acting as dispersants. The polar head group of inhibitors interacts with asphaltene particles while the alkyl tail extends into the solvent / oil forming a steric hindrance layer (Rogel and León, 2001). Inhibitors can also be effective at the molecular level, for example, dodecylbenzyl sulfonic acid disperses asphaltene aggregates to form a stable colloid when used in low concentration and dissolves asphaltenes to form a solution when used in higher concentration (Hashmi et al., 2012; Hashmi and Firoozabadi, 2013a). Inhibitors can delay the onset of asphaltene precipitation (AlSahhaf et al., 2002), decrease (or increase) the precipitated amount (Goual and Firoozabadi, 2004; Madhi et al., 2018) and reduce the particle size (Mansur et al., 2012). Inhibitors may also alter the structure of flocculated asphaltene from globular to filamentary (Goual et al., 2014; Goual and Sedghi, 2015). However, other potential mechanisms of inhibition must be considered. Being surface-active, inhibitors may themselves adsorb at solid surfaces and alter the asphaltene-surface interaction, potentially reducing adhesion of carbonaceous deposits (Kaimaki et al., 2018). Additionally, remedial use of additive molecules to remove asphaltene deposits is known (Hashmi and Firoozabadi, 2013b; Madhi et al., 2018; Trimble et al., 2008).

Trials of asphaltene inhibitors in the field are costly and time-consuming. Hence, it is necessary to find simple laboratory-based techniques that may provide information on the mechanism of action of asphaltene inhibitors and their performance (Gon and Fouchard, 2016; Lin et al., 2017; Marcano et al., 2015). Such techniques would enable facile pre-screening of inhibitors prior to field trials. Recently, it has been demonstrated that quartz crystal microbalance with dissipation monitoring (QCM-D) can be used to study the effect of inhibitor on asphaltene adsorption/deposition (Subramanian et al., 2018a), while a HPHT (high pressure high temperature)-QCM has been used to study inhibitor impact under field-representative conditions (Joonaki et al., 2018). The deposition behaviour of asphaltenes strongly depends on the environmental conditions encountered. In toluene, asphaltenes exist as a stable colloid of small nanoaggregates and individual molecules, and 
monolayer adsorption is observed (Campen et al., 2017). However, in heptane-toluene, asphaltenes exist as a destabilized colloid and multilayer deposition of asphaltenes occurs.

In this paper, we carry out particle size distribution analysis and QCM-D experiments to investigate the numerous potential mechanisms of action of an asphaltene inhibitor under different environmental conditions. The impact of colloid stability, governed by heptane-toluene ratio, on inhibitor performance is studied. The behaviours investigated include (i) the effect of inhibitor on the particle size distribution of asphaltene in heptane-toluene, (ii) the surface-adsorption of inhibitor and its performance as a barrier-type coating to prevent asphaltene adhesion, (iii) the remedial use of inhibitor for removing pre-deposited asphaltene films and (iv) the efficacy of inhibitor for preventing asphaltene deposition from destabilised dispersions in heptane-toluene. We show that the performance of an inhibitor varies depending on the conditions present and the degree of destabilisation of the asphaltenes.

\section{Experimental section}

\subsection{Materials and preparation techniques}

A crude oil sample (opaque dark brown/black liquid; density $=0.877 \mathrm{gcm}^{-3}$ and viscosity $=18.9 \mathrm{mPa} . \mathrm{s}$ at $20^{\circ} \mathrm{C}$ ) and a commercial formulated asphaltene inhibitor "Inhibitor A" (translucent orange liquid) were supplied by BP. The crude oil sample is stored at ambient temperature $\left(22^{\circ} \mathrm{C}\right)$ and under atmospheric pressure - thus most volatile light saturates would have evaporated, i.e. it is 'dead oil'. Inhibitor $A$ is known to contain polymeric dispersant molecules with polar hydroxyl head groups (polyols). The solvents: toluene (99.9\%, CHROMASOLV), n-heptane ( $\geq 99 \%$, CHROMASOLV) and acetone ( $\geq 99.8 \%$, CHROMASOLV) were acquired from Sigma-Aldrich and used without further purification. Asphaltene was extracted from crude oil using heptane as precipitant. Heptane was added to crude oil in a 40:1 mass ratio. The resulting heterogeneous mixture was sealed in an airtight bottle and agitated in an ultrasonic bath for 1 hour before storing in a dark cupboard for 1 week. After this time, the precipitate was collected by vacuum filtration on a PTFE filter with $0.45 \mu \mathrm{m}$ pore size (Merck Millipore) and rinsed with heptane until the filtrate was colourless. The precipitate was dried in an oven at $70^{\circ} \mathrm{C}$ for $1 \mathrm{~h}$ yielding asphaltene (dark brown/black solid, yield $=5.34 \mathrm{wt} \%$ ). The dried asphaltene was dissolved in toluene giving a $10 \mathrm{gL}^{-1}$ stock solution; this was agitated for $1 \mathrm{~h}$ in an ultrasonic bath before storing in a dark cupboard to equilibrate for 2 weeks. Asphaltene solutions were prepared from this stock solution: these were ultrasonicated for $5 \mathrm{~min}$ before use.

The viscosity and density of the solvents (heptane-toluene mixtures) and solutions of both asphaltene and Inhibitor A were measured using a Stabinger Viscometer (SVM 3000, Anton-Parr). Viscosity and density values (see Supplementary information SI 1) were needed for calculating centrifugation times (section 2.2), dynamic light scattering measurements (section 2.2) and fitting QCM-D data (section 2.3). The refractive index of heptane-toluene (see Supplementary information SI 2) was measured at 
the Na D-line using an Abbe refractometer with an external heated oil bath, while that of asphaltene $(\mathrm{nD} 20=1.7)$ was taken from the literature (Buckley, 1999; Castillo et al., 2010; Taylor et al., 2001).

Gold-coated quartz sensors, used for QCM-D adsorption studies, were acquired from Q-Sense (Biolin Scientific, Sweden). A QCM-D flow cell with Kalrez O-ring and gasket was also acquired from QSense. Quartz cuvettes with PTFE stoppers (Hellma-Analytics) were used for UV-vis and dynamic light scattering measurements. Before use, the sensors, dismantled flow cell and cuvettes were cleaned by ultrasonicating for $30 \mathrm{~min}$ in Hellmanex III liquid cleaning concentrate as 2 vol\% solution in DI water (resistivity $>18.2 \mathrm{M} \Omega \mathrm{cm}$, Milli-Q, Millipore). The parts were then thoroughly rinsed under running DI water and acetone before drying under a stream of nitrogen. The quartz sensor was plasma-cleaned under oxygen for 2 min (Atto Cleaner, Diener Electronic).

\subsection{Particle size distribution analysis}

The effect of inhibitor on the particle size distribution of asphaltene in heptane-toluene was determined by two different techniques: centrifugation/UV-vis spectroscopy (Tavakkoli et al., 2015) and dynamic light scattering (DLS). A solution containing a mixture of asphaltene $\left(1 \mathrm{gL}^{-1}\right)$ and Inhibitor $\mathrm{A}\left(0.1,1,10\right.$ or $\left.100 \mathrm{gL}^{-1}\right)$ in toluene was prepared. This solution was then mixed in a 1:9 volume ratio with heptane-toluene so that dispersions of asphaltene $\left(0.1 \mathrm{gL}^{-1}\right)$ with Inhibitor $\mathrm{A}(0.01$, $0.1,1$ or $10 \mathrm{gL}^{-1}$ ) in $0,50,60,70,80$ and 90 vol\% heptane were obtained. The resultant mixtures were agitated for $1 \mathrm{~min}$, before standing at room temperature $\left(22^{\circ} \mathrm{C}\right)$. After a destabilisation time of 10 min (i.e. the time elapsed since asphaltene mixed with heptane - an asphaltene precipitant), the mixtures were centrifuged to remove particles greater than 100 or $1000 \mathrm{~nm}$. Details of the centrifugation conditions can be found in the Supplementary information SI 3. After centrifugation, the supernatant liquid was diluted with toluene and a UV-vis spectrum obtained (USB4000-UV-vis, Ocean Optics). The concentration of asphaltene in the supernatant liquid (and thus the mass fraction precipitated) was determined from concentration-absorbance calibration data, see Supplementary information SI Figure S1.

For DLS, the same solution of asphaltene $\left(1 \mathrm{gL}^{-1}\right)$ and Inhibitor A in toluene was mixed in a 1:9 volume ratio with heptane-toluene in a cuvette with PTFE stopper. This mixture was agitated by hand for 10 seconds before immediately transferring to the DLS (Zetasizer Nano ZSP with $633 \mathrm{~nm}$ 'red' He$\mathrm{Ne}$ laser, Malvern Instruments). Measurements were made over a range of destabilisation times using non-invasive back scattering (NIBS) at an angle of $173^{\circ}$ and temperature of $20^{\circ} \mathrm{C}$.

Note that particle size measurements should be treated with caution, since both techniques assume that particles are spherical. In reality, particles may not be spherical, in which case their hydrodynamic diameter may not be accurately calculated from their diffusion coefficient using the Stokes-Einstein equation. 
A quartz-crystal microbalance with dissipation monitoring (QCM-D, Biolin Scientific) was used to monitor the adsorption and deposition of asphaltene and Inhibitor $A$ onto gold-coated quartz sensors. This apparatus monitors shifts in frequency $\left(\Delta f_{n} / n\right)$ and dissipation $\left(\Delta D_{n}\right)$ versus time as the liquid in contact with the sensor is successively changed. An AC voltage is applied to the quartz sensor so that it oscillates at its fundamental resonance frequency of $5 \mathrm{MHz}$. Intermittently, the driving voltage is switched off and the oscillation observed to decay exponentially. Dissipation (D) is given by:

$$
D=\frac{E_{\text {dissipated }}}{2 \pi E_{\text {stored }}}
$$

where $\mathrm{E}_{\text {dissipated }}$ is the energy dissipated during one oscillation period and $\mathrm{E}_{\text {stored }}$ is the total energy stored in the oscillating crystal (Rodahl et al., 1995). The crystal is also oscillated at odd overtones (n) of the fundamental frequency (i.e. $n=3,5,7,9,11$ and 13 having frequencies of $15,25,35,45,55$ and $65 \mathrm{MHz}$ respectively). The data was fitted using the Voigt viscoelastic model in Q-Tools software (Biolin Scientific), since $\Delta D_{n}>0$, the Sauerbrey mass could not be applied. Previously we found that the Voigt model could approximate the mass of asphaltene deposits (even those that were laterally heterogeneous), see supporting information to (Campen et al., 2018). The QCM-D technique has been described previously (Abudu and Goual, 2009; Dudášová et al., 2008a; Rodahl et al., 1995; Tavakkoli et al., 2014); details of how shifts in frequency and dissipation are related to changes in both the adsorbed mass and physical properties of the liquid can be found in the Supplementary information SI 4.

All QCM-D experiments were carried out in a flow cell at $20^{\circ} \mathrm{C}$. Before flowing asphaltene / inhibitor solutions, baselines were monitored in the respective solvents (toluene and heptane-toluene). Two pumps were used to flow liquid through the cell: an Ismatec Reglo 12-roller pump with Gore $100 \mathrm{CR}$ or Viton pump tubing and a MilliGAT HF pump from Global FIA. All other tubing was $0.8 \mathrm{~mm}$ internal diameter PTFE (Chemfluor, Saint Gobain) and connectors, valves, fittings and ferrules were of PEEK and ETFE (Kinesis).

For adsorption studies in toluene, only one pump was used to pull liquids through the cell at a flow rate of $6 \mu \mathrm{Ls}^{-1}$. For deposition studies in heptane-toluene both pumps were operated to push liquids towards a mixing T-junction; the liquid then flowed through a PTFE tube of $60 \mathrm{~cm}$ length before reaching the flow cell, Fig 1. Asphaltene / inhibitor in toluene was flowed at a rate of $2 \mu \mathrm{Ls}^{-1}$ and heptane-toluene at $18 \mu \mathrm{Ls}^{-1}$, giving a flow rate after the T-junction of $20 \mu \mathrm{Ls}^{-1}$. Taking into account the internal volume of the flow path and the flow rate, the destabilisation time between mixing at the Tjunction and the quartz sensor was $20 \mathrm{~s}$, while the residency time above the sensor surface inside the QCM-D flow cell was $2 \mathrm{~s}$. Low-cracking pressure in-line check valves were placed before the Tjunction to prevent backflow of one liquid stream to the other (Kinesis). 


\subsection{Optical microscopy and atomic force microscopy of deposited films}

Deposited films were investigated by optical microscopy and atomic force microscopy (AFM). Films deposited on gold-coated quartz sensors during QCM-D experiments were rinsed inside the QCM flow cell with heptane-toluene at the same heptane volume fraction used for deposition. The sensors were then removed from the cell and the solvent allowed to evaporate. A Zeiss optical microscope with white light source and camera attachment was used to acquire optical micrographs of the deposited films. Tapping mode AFM was carried out using a Multimode SPM with Nanoscope V controller (Bruker). Measurements were made in air at ambient temperature $\left(22^{\circ} \mathrm{C}\right)$ using soft-tapping RTESPA-150 probes with silicon tips, nominal spring constant of $5 \mathrm{Nm}^{-1}$ and resonance frequency of $150 \mathrm{kHz}$ (Bruker).

\section{Results and discussion}

3.1 Inhibition behaviour in bulk: Effect of inhibitor on the particle size distribution of asphaltene

The effect of Inhibitor A on the particle size distribution of asphaltene at a destabilisation time of 10 minutes is shown in Fig 2. In the absence of inhibitor, it is observed that addition of heptane leads to aggregation of asphaltene. Particles greater than $1000 \mathrm{~nm}$ in diameter (black) are observed at 70 vol\% heptane and above - the mass fraction of asphaltene existing as particles of this size increases with increasing heptane vol\%. Particles of 100-1000 nm diameter (dark grey) are observed at 60 vol\% heptane and above - the mass fraction existing as particles of this size shows marginal increase with increasing heptane vol\%. At 50 vol\% heptane, all particles are less than $100 \mathrm{~nm}$ in diameter. Note that destabilized particles which are smaller than $100 \mathrm{~nm}$ may exist and have previously been shown to deposit (Vilas Bôas Fávero et al., 2016).

Addition of inhibitor alters the particle size distribution. Particles greater than $1000 \mathrm{~nm}$ in diameter do not form at inhibitor concentrations of $0.1 \mathrm{gL}^{-1}$ and over. At the lowest inhibitor concentration of 0.01 $\mathrm{gL}^{-1}$, particles $>1000 \mathrm{~nm}$ do exist at high heptane vol\%, however they represent a much smaller mass fraction than without inhibitor. With inhibitor, the mass fraction of asphaltene existing as particles of 100 to $1000 \mathrm{~nm}$ size increases with increasing heptane vol\%. Use of a higher concentration of inhibitor leads to slightly better stabilisation of asphaltene. For a given heptane vol\%, the mass fraction of asphaltene existing as particles of 100-1000 nm diameter is smaller at higher inhibitor concentration.

The particle size distribution was also investigated by DLS, Fig 3. Without inhibitor, aggregation is observed at 70 vol\% heptane and above. The particle size distribution evolves over the $10 \mathrm{~min}$ destabilisation time; this is most evident at 70 vol\% heptane where the distribution changes from monomodal at $2 \mathrm{~min}$ (peak at $615 \mathrm{~nm}$ ) to bimodal at $10 \mathrm{~min}$ (peaks at 1720 and $4800 \mathrm{~nm}$ ). In 80 and 
90 vol\% heptane, this transition is faster. With $10 \mathrm{gL}^{-1}$ inhibitor, particles greater than $1000 \mathrm{~nm}$ are not observed, and particle size is generally over an order of magnitude lower than that observed without inhibitor. At 70 vol\% heptane the distribution is bimodal (peaks at 60 and $165 \mathrm{~nm}$ ). At 80 and 90 vol\% heptane, the distribution is monomodal (peak at $180 \mathrm{~nm}$ ).

The effect of inhibitor concentration on the particle size distribution was investigated by DLS for dispersions in 90 vol\% heptane, Fig 4. For concentrations of $0.1-10 \mathrm{gL}^{-1}$, the particle size distribution is approximately constant with time and concentration (monomodal distribution centred about $180 \mathrm{~nm}$ ). At low inhibitor concentrations of 0.01 and $0.001 \mathrm{gL}^{-1}$, particles $>1000 \mathrm{~nm}$ form. The time at which particles $>1000 \mathrm{~nm}$ are first observed (t (floc)) decreases with decreasing concentration. Hence, Inhibitor A acts to slow the rate of formation of large aggregates (delay flocculation). The finding that aggregate size is approximately constant with inhibitor concentration for higher inhibitor concentrations $\left(\geq 0.1 \mathrm{gL}^{-1}\right)$ is in agreement with a previous molecular thermodynamics study of asphaltene-inhibitor aggregates in toluene (Rogel, 2011); at high inhibitor concentration, aggregates contained a larger number of inhibitor molecules but a smaller number of asphaltene molecules, resulting in an approximately unaltered overall aggregate size. It is noted that our study is in heptane-toluene and the size of our aggregates, being $\sim 180 \mathrm{~nm}$, is much larger than in the model.

DLS results are in broad agreement with the centrifugation study. One discrepancy between the two techniques is that particles smaller than $100 \mathrm{~nm}$ exiting beyond the flocculation point, e.g. in $70 \mathrm{vol} \%$ heptane are not detected by DLS, even though they make up a considerable proportion $(>50 \%$ mass fraction) of asphaltene. It is proposed that DLS is not sensitive to these small particles when they are co-existing with larger particles which are more effective light-scatterers.

In summary, it is observed that Inhibitor A acts as an effective anti-agglomerant under the conditions studied. Generally, inhibitor addition results in the formation of aggregates of about $180 \mathrm{~nm}$ size, while preventing the formation of large flocculent aggregates (i.e. particles greater than $1000 \mathrm{~nm}$ ) in heptane-toluene. It is thus postulated that the mechanism of action of the inhibitor is as a dispersant, rather than a solvency-improver, since inhibitor is unable to completely prevent aggregate growth, even when used in high concentration. Note however, that we are unable to conclusively rule out that inhibitor is also effective at the molecular level, since we do not know the ratio of monomernanoaggregate for particles $<100 \mathrm{~nm}$. Interestingly, inhibitor does decrease the particle size in 60 vol\% heptane from $10 \mathrm{~nm}$ to $4 \mathrm{~nm}$ (Fig. 3). The minimum concentration of inhibitor required to prevent floc formation in our studies $\left(0.1 \mathrm{gL}^{-1}=143 \mathrm{ppm}\right)$ is within the typical range of treat rates for this inhibitor in the field (100 - 200 ppm), see Table 1.

3.2 Inhibition behaviour at surface: Adsorption and deposition of asphaltene inhibitor onto a gold surface 
QCM-D experiments were carried out to monitor adsorption of Inhibitor A onto gold surface from solution in toluene. Gold is used as a model metallic surface (piping systems in the Oil and Gas industry are typically constructed from stainless steel) since it is relatively inert, easily-cleaned under oxygen-plasma and has previously been found to give reproducible results in asphaltene adsorption studies (Campen et al., 2017). When inhibitor is flowed through the cell, negative shifts in frequency are observed - these are indicative of adsorption of molecules onto the gold surface, Fig 5 . After an adsorption time of $30 \mathrm{~min}$, the surface is rinsed by flowing toluene; the frequency does not return to its baseline value, suggesting that the inhibitor molecules are strongly adsorbed to the surface, as expected due to their polar head groups. The adsorption-rinsing cycle is repeated at successively higher Inhibitor A concentrations from 0.01 to $100 \mathrm{gL}^{-1}$. The rate of adsorption increases with increasing inhibitor concentration. At high concentrations of 1,10 and $100 \mathrm{gL}^{-1}$, the adsorbed mass plateaus. While at lower concentrations, equilibrium is not reached within the adsorption time. Small positive shifts in dissipation suggest that the adsorbed film is slightly viscoelastic. Liquid loading (due to the increased viscosity and density of the inhibitor solution respective to toluene) is particularly apparent at high concentration and is recognisable by spreading of both frequency and dissipation of different overtones and also very large dissipation shifts. After correcting for liquid loading effects, the adsorbed mass before and after rinsing is calculated, Table 2. The mass of a monolayer of Inhibitor A is about $340 \mathrm{ngcm}^{-2}$, which is achieved at a concentration of $1 \mathrm{gL}^{-1}$ within our experimental timeframe. The density of the Inhibitor A monolayer is not known, however if we assume a density of 1 $\mathrm{gcm}^{-3}$, it is approximated that the monolayer has a thickness of $3.4 \mathrm{~nm}$. From the Voigt viscoelastic model, this monolayer has a shear viscosity of $2.3 \mathrm{mPa} \cdot \mathrm{s}$ and shear elasticity of $0.65 \mathrm{MPa}$.

Previously it has been reported that an adsorbed protein layer on methyl-terminated gold had viscosity and elasticity of $1.8 \mathrm{mPa} \cdot \mathrm{s}$ and $0.066 \mathrm{MPa}$ respectively. After cross-linking (giving a 3D network of chemically bonded proteins) these increased to $6 \mathrm{mPa} \cdot \mathrm{s}$ and $0.3 \mathrm{MPa}$ respectively; crosslinking also caused a reduction in thickness from 22.4 to $7.3 \mathrm{~nm}$ (Höök et al., 2001). Adsorbed protein films of $3.2-6.2 \mathrm{~nm}$ thickness on polyethersulfone substrates had viscosity of $2.3-10 \mathrm{mPa} \cdot \mathrm{s}$ and elasticity of $0.1-0.92 \mathrm{MPa}$ (Liu and Kim, 2009). Elsewhere, polyelectrolyte multilayers on silica were found to have a viscosity of $3-20 \mathrm{mPa} \cdot \mathrm{s}$ and elasticity of $0.14-2.7 \mathrm{MPa}$; both viscosity and elasticity increased with the number of layers and were found to be strongly dependent on the chemistry of the outermost layer (Notley et al., 2005). Films of adsorbed cross-linked agarose gel and covalentlybound (but not cross-linked) thiol-tagged polyethylene glycol brushes on gold surfaces exhibited different viscoelastic properties; at a surface coverage of $500 \mathrm{ngcm}^{-2}$ the viscosity and elasticity were $2.5 \mathrm{mPa} \cdot \mathrm{s}$ and $0.2 \mathrm{MPa}$ respectively for the gel, and $1 \mathrm{mPa} \cdot \mathrm{s}$ and $0.05 \mathrm{MPa}$ for the brush (Dutta and Belfort, 2007). Hence, the gel was more rigid than the brush. The viscoelastic properties of the Inhibitor A monolayer are thus within the bounds observed previously for other thin films, and are more similar to those of an adsorbed rigid gel-like film than a non-crosslinked polymer brush.

Experiments were made to determine whether Inhibitor A forms thicker films when the heptane vol\% is increased, due to, for example, multilayer adsorption (self-assembled multilayer formation). Note, 
complete solubility of Inhibitor A in both toluene and heptane was observed for concentrations up to $100 \mathrm{gL}^{-1}$, i.e. solutions were transparent and no opacity or precipitation was observed. For these experiments, the 2-pump system was used. An adsorbed inhibitor monolayer was initially formed in toluene, after which inhibitor was flowed as solutions in 60 and 80 vol\% heptane. The frequency and dissipation shifts are given in Fig 6. Note each flow step in heptane:toluene is followed by a flow step in toluene. After accounting for the liquid loading effects due to the altered viscosity and density of the test solutions (Inhibitor A in heptane-toluene) respective to toluene, it is found that the adsorbed mass does not change when the heptane vol\% is increased (see pink arrows). The mechanical properties of the inhibitor film in heptane-toluene are similar to those in toluene. This suggests the adsorbed amount of Inhibitor A is not affected by subsequent changes in vol\% heptane, and Inhibitor A does not in itself exhibit an increased tendency to adsorb / deposit when the heptane vol\% is increased.

\subsection{Control studies: Adsorption and deposition of asphaltene onto gold without inhibitor}

Previously we have used QCM-D to investigate the adsorption from toluene (Campen et al., 2017) and the deposition from heptane-toluene (Campen et al., 2018) of asphaltene samples extracted from the same crude oil onto gold. In brief, asphaltene adsorbs from toluene forming a thin film of monomer-nanoaggregates which remains upon toluene-rinsing. The adsorption data can be fitted by the Langmuir adsorption isotherm, giving the areal mass of a complete monolayer as $804 \mathrm{ngcm}^{-2}$. Assuming that asphaltenes have a density of $1.2 \mathrm{gcm}^{-3}$ (Barrera et al., 2013; Yarranton et al., 2013), it is approximated that the monolayer thickness is $6.7 \mathrm{~nm}$. Note this is more than twice the mass of a monolayer of Inhibitor A.

When asphaltenes mix with heptane-toluene, they are destabilised and aggregate. Using the 2-pump system it was found that asphaltene aggregates deposit from heptane-toluene, forming multilayer films. The rate of asphaltene deposition and the nature of the depositing species depend on both the heptane-toluene ratio and the destabilisation time (the time between asphaltene mixing with heptane and the mixture arriving at the QCM-D sensor). Two main behaviours are observed: at low heptane volume fractions (and short destabilisation time) deposition of small submicrometer aggregates occurs resulting in a uniform deposit layer, see Fig 7 (a). At high heptane volume fractions (and longer destabilisation time), asphaltene flocculates before reaching the QCM-D sensor and hence deposition of large species (including flocs $>10 \mu \mathrm{m}$ ) occurs resulting in a patchy deposit layer, see Fig 7 (b).

\subsection{Inhibition behaviour at surface: Efficacy of inhibitor as a barrier-type coating}

Inhibitor A was found to be effective as a barrier-type coating in toluene, Fig 8. Inhibitor A was adsorbed onto gold from $100 \mathrm{gL}^{-1}$ solution in toluene before rinsing with toluene to give a monolayer 
film. Asphaltene was then flowed either as 0.1 or $1 \mathrm{gL}^{-1}$ solution in toluene. No significant change in the adsorbed mass is observed (compare Fig $8(a)$ and (b) with and without inhibitor barrier layer). Conversely, Inhibitor A was found to be ineffective as a barrier-type coating in heptane-toluene (Fig 9). When the heptane vol\% is increased, multilayer deposition of asphaltene occurs on top of the preadsorbed inhibitor monolayer (pre-formed in toluene), note large negative shifts in frequency and positive shifts in dissipation in Fig 9. After the deposition, the heptane vol\% is returned to zero (i.e. asphaltene in toluene) and the multilayer deposit is removed. The mass of the remaining monolayer film is similar to that prior to the deposition, however the dissipation is slightly increased (see inset in Fig 9 bottom). Since the mass of a monolayer of asphaltene is much greater than that of inhibitor, our results suggest that significant exchange of inhibitor by asphaltene does not occur in this basal monolayer. However, a small amount of swelling / exchange may occur, causing an increase in dissipation.

The results indicate that in toluene, where asphaltene is well-dispersed and exists as a mixture of individual molecules and small nano-aggregates, asphaltene is unable to displace a pre-adsorbed monolayer of inhibitor. Asphaltene is relatively stable in solution and does not adsorb on top of the inhibitor monolayer. Asphaltene adsorption from toluene requires a vacant site at the gold surface. However, when asphaltene is destabilised by mixing with heptane, multilayer-deposition of asphaltene occurs on top of the pre-adsorbed inhibitor monolayer. Destabilised asphaltenes in heptane-toluene is insensitive to the nature of the surface, readily depositing onto films of asphaltene or inhibitor, and not requiring a vacant site at the gold surface.

\subsection{Remediation behaviour: Efficacy of inhibitor for removing pre-deposited asphaltene films}

Inhibitor A was found to displace a pre-adsorbed monolayer film of asphaltene in toluene, Fig 10. Note how the frequency increases when inhibitor solution is flowed over the pre-formed asphaltene monolayer, suggesting mass loss. The overall frequency shift after inhibitor rinsing, is similar to that previously observed for a monolayer of inhibitor (Fig 8 (a)), suggesting that inhibitor displaces asphaltene. The rate of displacement increases with increasing inhibitor concentration. A complete monolayer of inhibitor has lower relative dissipation than a thin film of asphaltene (see Fig 10 (b) and (c)), however, partial displacement results in a mixed asphaltene-inhibitor film of higher dissipation, Fig 10 (a). This result (together with that in section 3.4) suggests that the inhibitor-gold interaction is stronger than the asphaltene-gold interaction.

In heptane-toluene, on the other hand, Inhibitor A is relatively ineffective at removing a pre-deposited asphaltene film. After asphaltene deposition from $60 \mathrm{vol} \%$ heptane, the asphaltene deposit is rinsed at 60 vol\% heptane with increasing concentration of Inhibitor A from 0 to $10 \mathrm{gL}^{-1}$, Fig 11 . Inhibitor A cannot readily remove the thick multilayer deposit in 60 vol\% heptane (note how the frequency shift is largely unchanged) and significant mass loss is only achieved when the heptane volume fraction is lowered to 0 vol\%. However, properties of the film change during rinsing in 60 vol\% heptane with 
Inhibitor A. Increases in dissipation and the spread of dissipation among different overtones are observed, indicative of film swelling. The relative change in dissipation supports that the film is becoming softer, Fig 12 (a). Fitting of the data in Fig 11 by the Voigt viscoelastic model suggests that the film's mechanical properties change during rinsing, while the mass remains approximately constant, Fig 12 (b). During asphaltene deposition, both shear viscosity and shear elasticity increase with increasing deposit thickness (mass). During rinsing, both shear elasticity and shear viscosity decrease; these decreases commence before inhibitor is flowed, hence rinsing the deposit with the same heptane vol \% used for deposition induces changes in the film. The Voigt fitting assumes a constant density of the deposited film $\left(1.2 \mathrm{gcm}^{-3}\right)$, however, in reality the density of the film may change throughout the experiment. Note, we cannot decipher the composition of the film. Hence, the mass of asphaltene could potentially decrease during rinsing (although frequency remains constant) if the film were to be swollen by inhibitor or solvent, since these molecules would generate their own frequency (and mass) contribution, which cannot be separated from the bulk properties of the film. Our results support previous AFM experiments looking at the effect of this same inhibitor, which was added to crude oil before introducing a steel surface (Kaimaki et al., 2018), and revealed that the dried deposited film had a crack pattern. It is suggested that the deposited asphaltene/inhibitor film swelled by several \% before drying, resulting in crack formation. Samples prepared without inhibitor did not show this pattern.

The results suggest that Inhibitor A may have limited scope for remediation application in the field (i.e. to remove thick pre-formed multilayer deposits), which is expected as it is marketed and deployed as an asphaltene inhibitor. However, Inhibitor A can displace thin monolayer asphaltene films in good solvent (toluene). This could be of use if a solvency improver (xylene, toluene, or other aromatic solvent) is flowed together with Inhibitor A, as it may aid complete removal of asphaltene deposit leaving instead a monolayer of inhibitor. However, deployment in this way may be limited in its attractiveness since, after remediation and once standard operating conditions are resumed, destabilised asphaltene aggregates will then likely deposit on top of this monolayer of inhibitor (section 3.4). Note that in our study, we do not consider long-time aging of asphaltene deposits. Aging of asphaltene deposits can lead to greater surface adhesion and make their removal by toluene-rinsing more difficult (Vargas, 2016). A pre-adsorbed inhibitor film, although unable to prevent deposition of destabilised asphaltenes, may decrease deposit adhesion upon aging (Kaimaki et al., 2018).

\subsection{Inhibition mechanism: Carbonaceous materials deposition from asphaltene-inhibitor mixtures}

Adsorption from mixed asphaltene-inhibitor solutions in toluene onto gold was investigated, Fig 13. The initial rate of asphaltene adsorption is greater than that of inhibitor, however, over longer timeframes, inhibitor displaces initially adsorbed asphaltene, resulting in a monolayer of inhibitor. The rate of asphaltene displacement increases with increasing inhibitor concentration, see Fig 13 (a) vs. 
(b). The properties of the film change with time during adsorption, highlighting the changing composition, Fig 13 (c). The relative dissipation at initial time (Fig 13 (c)) corresponds to that previously observed for a monolayer of asphaltene (Fig 10 (a) bottom). The initial rate of asphaltene adsorption is independent of inhibitor concentration, (see initial slope of the curves, Fig 13 (d)), and the same as that of pure asphaltene in toluene, crosses in inset to Fig 13 (d), suggesting that free asphaltene exists in toluene and that asphaltene-inhibitor interactions only become important when heptane is added. Note that the initial rate of inhibitor adsorption, open circles in inset to Fig 13 (d), is slower than that of asphaltene. Alternatively, inhibitor-asphaltene hetero-aggregates may have formed in the solution. If they adsorb at the same rate as asphaltene nanoaggregates in toluene, we may in fact be observing adsorption of hetero-aggregates, followed by their collapse, resulting in a monolayer of inhibitor and loss of asphaltene to the bulk liquid. Elsewhere, collapse of adsorbed lipid vesicles to form supported lipid bilayers has been observed by QCM-D, and is typically accompanied by a significant decrease in dissipation (Keller and Kasemo, 1998; Richter et al., 2003). In our case the relative change in dissipation is small (Fig 13 (c)), lending support to the former interpretation of asphaltene displacement by inhibitor.

Deposition from mixed asphaltene-inhibitor dispersions in heptane-toluene was investigated using the 2-pump system. Asphaltene was premixed with Inhibitor A in toluene, prior to mixing with heptanetoluene at the T-junction, as shown in Fig 1 . This experiment replicates the scenario where inhibitor is injected into a production well or near well-bore (where asphaltene tends to be stable), prior to its flowing to the surface (and ensuing destabilisation). In 60 vol\% heptane, addition of inhibitor at all concentrations studied reduces the rate of deposition, Fig 14 (a) and (b). The rate of deposition is approximately constant with time and decreases with increasing inhibitor concentration from 12.1 $\mathrm{ngcm}^{-2} \mathrm{~s}^{-1}$ without inhibitor to $0.054 \mathrm{ngcm}^{-2} \mathrm{~s}^{-1}$ at the maximum tested inhibitor concentration of 50 $g L^{-1}$.

In 80 vol\% heptane there is no clear trend of deposition inhibition behaviour. When added in low but field representative - concentration ( 0.01 or $\left.0.1 \mathrm{gL}^{-1}\right)$, inhibitor reduces the deposited mass over the timeframe studied. Without inhibitor, deposition proceeds at decreasing rate with time (as previously observed under similar conditions, where the depositing species were flocs), while inhibitor addition results in a constant deposition rate (as previously observed when the depositing species were submicrometer aggregates (Campen et al., 2018), inset Fig 14 (c)). Hence at longer deposition times, inhibitor addition may eventually lead to a greater overall deposited mass. Note that the average deposition rate for the time-step $1500-1700 \mathrm{~s}$ is $1.89,2.80$ and $3.02 \mathrm{ngcm}^{-2} \mathrm{~s}^{-1}$ at inhibitor concentrations of $0,0.01$ and $0.1 \mathrm{gL}^{-1}$ respectively. When added in higher concentrations (1-50 $\left.\mathrm{gL}^{-1}\right)$, inhibitor tends to increase the deposited mass, Fig 14 (d). At concentrations $>1 \mathrm{gL}^{-1}$, the dose rate is several orders of magnitude higher than that typically deployed in the field (Table 1), and so would be considered a significant inhibitor over-treatment. Unusual behaviour is observed at $50 \mathrm{gL}^{-1}$, there is a delay in deposition onset at short times, while at longer times the deposition rate is constant but slower than that observed at $10 \mathrm{gL}^{-1}$. Elsewhere, it has been noted that inhibitor-inhibitor interactions and inhibitor self-aggregation may negatively impact performance at high inhibitor concentration 
(Barcenas et al., 2008; Madhi et al., 2018). However, in this study we do not observe a negative impact of high inhibitor concentration on particle size for the maximum tested concentration of 10 $\mathrm{gL}^{-1}$, see Fig 2 and 3.

The rate of deposition based on the results in Fig 14 is estimated see Fig 15. The average rate is calculated for 60 vol\% heptane while the instantaneous rate at $t=1000 \mathrm{~s}$ is calculated for 80 vol\% heptane, since here the rates were not always constant with time. The relative rate is obtained by dividing the deposition rate by that observed without inhibitor. In 60 vol\% heptane, inhibitor acts to decrease the relative rate, Fig 15 (a). Note that inhibitor efficiency seems to decrease with increasing concentration, since a disproportionately large concentration is required to effectively slow deposition (inhibitor concentration is plotted on a log scale!). In 80 vol\% heptane, a low concentration of inhibitor $\left(0.01-1 \mathrm{gL}^{-1}\right)$ has little effect on the relative rate while higher concentrations lead to greatly increased deposition rates, Fig 15 (b).

The frequency-dissipation relationship during depositions from 60 vol\% heptane is not dramatically altered by inhibitor, Fig 16 (a) and (b). In all cases dissipation increases with increasing overtone number. This suggests that the mechanical properties of the deposited films are broadly unaltered by inhibitor addition. In 80 vol\% heptane, however, the frequency-dissipation relationship changes due to inhibitor addition, suggesting that the mechanical properties of the deposited film are altered, Fig 16 (c) and (d). Without inhibitor, dissipation from the different overtones overlap (suggesting deposition of flocs). However, with inhibitor, dissipation increases with increasing overtone number (suggesting deposition of smaller submicrometer particles) (Campen et al., 2018). AFM confirms that addition of inhibitor changes the morphology of the deposited film at 80 vol\% heptane, Fig 17. This observation is supported by the particle size distribution experiments (section 3.1). Inhibitor A prevents flocculation of asphaltene in $80 \mathrm{vol} \%$ heptane, however, destabilised aggregates of intermediate size do form and deposit onto surfaces (Fig 17 (b) - (d)). Seemingly, Inhibitor A is capable of dispersing aggregates and preventing growth of particles larger than $1000 \mathrm{~nm}$, however, it is unable to prevent these same particles from sticking to the surface.

Aged asphaltene dispersions in heptane-toluene have been shown not to deposit and it is small destabilised particles with a high tendency to aggregate which are chiefly responsible for surface deposition (Campen et al., 2018; Hoepfner et al., 2013). Perhaps the same is true of asphaltene/inhibitor dispersions. Upon addition of heptane, the initial rate of asphaltene aggregation is fast and reaction-limited, while at longer times, the rate of asphaltene aggregation is slower and diffusion-limited (Yudin et al., 1998). It may be that slow kinetics of inhibitor adsorption onto asphaltene particles allows aggregation and surface deposition to occur before inhibitor can stabilise particles. It is interesting to note that $0.1 \mathrm{gL}^{-1}$ asphaltene in toluene had a higher initial rate of adsorption onto gold than $10 \mathrm{gL}^{-1}$ Inhibitor A (Fig 13 (d) inset). So, perhaps, in the early stages of destabilisation by heptane, asphaltene-asphaltene interactions occur at a faster rate than asphalteneinhibitor interactions. Use of a higher inhibitor concentration would increase the rate of inhibitor adsorption onto asphaltene particles, thereby shielding asphaltene aggregates more quickly, and 
lowering the deposition rate, as seen in Fig 15 (a). Note that use of higher inhibitor concentration decreases the number of particles of intermediate $100-1000 \mathrm{~nm}$ size in $60 \mathrm{vol} \%$ heptane, Fig 2 (b). It is hypothesized that deposition chiefly occurs during the period where the particle size (or number of particles of $\sim 180 \mathrm{~nm}$ size) is still increasing, i.e. before it reaches its equilibrium distribution.

Note that QCM-D measurements give a snapshot view of what is happening at a particular point in time after a destabilisation event; deposition occurring in the tubing prior to the QCM cell is not monitored. At 80 vol\% heptane, significant deposition can occur in the tubing upstream of the QCM cell and before the formation of flocculent particles (Campen et al., 2018). Under certain conditions where Inhibitor A increases deposition inside the QCM cell, it may in fact reduce deposition in the tubing before the cell. Hence, the overall impact of introduction of Inhibitor A may not be completely represented in Fig 14 (d). An illustration of the proposed deposition behaviour with and without inhibitor is given in Fig 18. Inhibitor A decreases deposition of small particles at short destabilisation time (i.e. behaviour in 60 vol\% heptane). However, at longer destabilisation time, formation of flocs (which pose a lesser deposition threat) is prevented, and smaller destabilised aggregates deposit instead. With Inhibitor $A$, a slower growing deposit forms over a longer section of pipe. While without Inhibitor A, a faster growing deposit forms over a shorter section of pipe.

The concentration of Inhibitor A used in these studies is compared to the typical treat rate in the field (100-200 ppm up to maximum of $1000 \mathrm{ppm}$ in crude oil), see Table 1. Whilst field-representative dose rates do effectively reduce the rate of deposition (Fig 14 (a)), it is clear from our experiments that it is necessary to use a high concentration of Inhibitor A (132000 ppm) to prevent deposition from 60 vol\% heptane, Fig 14 (b). However, there are numerous differences between our experiments and depressurizing live crude oil encountered in the field. For example, our sample is extracted asphaltene in heptane-toluene rather than live crude oil; hence we do not have contributions from the maltene (heptane-soluble) fractions. The concentration of asphaltene we use $\left(0.1 \mathrm{gL}^{-1}\right.$ in heptanetoluene) is much lower than that in the dead crude oil $\left(60.7 \mathrm{gL}^{-1}\right.$, density of crude oil at $20^{\circ} \mathrm{C}$ is 0.877 $\mathrm{gcm}^{-3}$ and asphaltene content is $5.32 \mathrm{wt} \%$ ). The flow conditions are known to be important and in our case the flow is laminar ( $R e=49$ in the tubing before the $Q C M$ and $R e=2.7$ inside the $Q C M)$, while in reality it would be turbulent $\left(R e=10^{4}-10^{6}\right)$ (Paes et al., 2015). Additionally, the temperature and pressure are different. Although in this study we artificially induce asphaltene destabilisation by adding n-heptane, we expect that future QCM-D studies will be able to use more field representative conditions (pressure, temperature and flow). Inhibitor efficiency may appear better when using dead crude oil samples, kept at atmospheric pressure, than live ones, which have been kept under high pressure (Jennings et al., 2018). Thus, using field-representative conditions is key to better predicting inhibitor performance.

This study highlights that the efficacy of inhibitor depends on the degree of destabilisation. Although inhibitor prevents asphaltene flocculation, destabilized particles of intermediate $(100-1000 \mathrm{~nm})$ or small (<100 nm) size may still deposit. Previously, we (Campen et al., 2018) and others (Hoepfner et al., 2013) have seen that it is not large flocculent particles, but rather submicrometer destabilised 
aggregates that pose significant deposition issues. Hence, preventing or slowing flocculation may be undesirable. It is hypothesized that the nature of depositing particles in 80 vol\% heptane at short destabilisation time (i.e. upstream of the QCM cell) is analogous to that in 60 vol\% heptane inside the QCM cell, although the concentration (mass fraction) of destabilised particles will be greater for 80 vol\% heptane. Similarly, we hypothesize that the nature of depositing particles in 60 vol\% heptane at long destabilisation time (i.e. downstream of the QCM cell) is analogous to that in 80 vol\% heptane inside the QCM cell, although here the concentration of destabilised particles will be much lower for 60 vol\% heptane. These hypotheses are based on previous QCM-D measurements of asphaltenes which found that the measured frequency-dissipation response depended on the nature of the deposited film (i.e. whether it consisted of smaller aggregates or large flocs) which was sensitive to destabilisation time and heptane vol\%. (Slower aggregation kinetics at lower heptane vol\% means that it takes longer for the destabilised asphaltenes to reach a given particle size distribution.) Thus, it is speculated that targeted introduction of inhibitor in the petroleum production pipeline may alleviate deposition at a given position (behaviour in 60 vol\% heptane) while simultaneously exacerbating deposition later on (behaviour in 80 vol\% heptane), effectively pushing the deposition problem further downstream. If proven correct, models to predict the likely position and rate of carbonaceous materials deposition in oil pipes will need to be modified to reflect inhibitor impact.

\section{Conclusions}

Combined particle size distribution studies by centrifugation and dynamic light scattering, together with adsorption / deposition experiments by QCM-D, can provide fundamental information on the mechanisms of action of formulated additive packages to prevent the formation of carbonaceous deposits during petroleum production. Such studies may prove beneficial prior to field trials of additives.

A summary of the observed behaviours of the tested additive package, an asphaltene inhibitor, is given in Table 3. The inhibitor was shown to prevent flocculation of destabilised asphaltene in heptane-toluene. The inhibitor also exhibited strong adsorption onto gold surfaces. A pre-adsorbed inhibitor monolayer was able to prevent adsorption of asphaltene from solution in toluene. When inhibitor solution in toluene was flowed over a surface with pre-adsorbed asphaltene monolayer, it was able to displace this asphaltene monolayer.

The ability of Inhibitor A to retard deposition of asphaltene from destabilised dispersions in heptanetoluene varies depending on the heptane vol \%. At low heptane volume fraction (60 vol\%), where destabilised asphaltenes deposit as submicrometer aggregates, inhibitor acts to slow the rate of deposition. When high heptane volume fractions are used ( $80 \mathrm{vol} \%$ ), which would otherwise result in flocculation of asphaltene, addition of inhibitor may increase the deposited mass. Here, addition of inhibitor alters the nature of the deposited film from that consisting of flocculent particles, to that consisting of smaller submicrometer aggregates. 


\section{Acknowledgments}

We acknowledge the funding and technical support from BP through the BP International Centre for Advanced Materials (BP-ICAM) which made this research possible. The authors thank Nalco Champion for supplying the formulated asphaltene inhibitor used in this research. The authors would also like to thank Dr Colm Durkan and Ms Maria Kaimaki for very helpful discussion.

\section{Declaration of Interest}

Declarations of interest: none.

\section{Supporting Information}

Supporting information can be found in one document which contains:

SI 1 Viscosity and density of test liquids

SI 2 Refractive index of test liquids

SI 3 Particle size distribution by centrifugation-UV-vis spectroscopy

SI 4 QCM-D fundamentals 


\section{References}

Abudu, A., Goual, L., 2009. Adsorption of Crude Oil on Surfaces Using Quartz Crystal Microbalance with Dissipation (QCM-D) under Flow Conditions. Energy \& Fuels 23, 1237-1248. https://doi.org/10.1021/ef800616x

Acevedo, S., Ranaudo, M.A., Escobar, G., Gutiérrez, L., Ortega, P., 1995. Adsorption of asphaltenes and resins on organic and inorganic substrates and their correlation with precipitation problems in production well tubing. Fuel 74, 595-598. https://doi.org/https://doi.org/10.1016/00162361(95)98363-J

Adams, J.J., 2014. Asphaltene adsorption, a literature review. Energy and Fuels 28, 2831-2856. https://doi.org/10.1021/ef500282p

Al-Sahhaf, T.A., Fahim, M.A., Elkilani, A.S., 2002. Retardation of asphaltene precipitation by addition of toluene, resins, deasphalted oil and surfactants. Fluid Phase Equilib. 194-197, 1045-1057. https://doi.org/10.1016/S0378-3812(01)00702-6

Al Sultan, A., Zirrahi, M., Hassanzadeh, H., Abedi, J., 2018. Effect of the Surfactant on Asphaltene Deposition on Stainless-Steel and Glass Surfaces. Energy and Fuels 32, 5635-5642. https://doi.org/10.1021/acs.energyfuels.8b00215

Alnaimi, F.B.I., Mazraeh, A.A., Sahari, K., Weria, K., Moslem, Y., 2016. Design of a multi-diameter inline cleaning and fault detection pipe pigging device, in: 2015 IEEE International Symposium on Robotics and Intelligent Sensors (IRIS). pp. 258-265. https://doi.org/10.1109/iris.2015.7451622

Barcenas, M., Orea, P., Buenrostro-González, E., Zamudio-Rivera, L.S., Duda, Y., 2008. Study of medium effect on asphaltene agglomeration inhibitor efficiency. Energy and Fuels 22, 19171922. https://doi.org/10.1021/ef700773m

Barrera, D.M., Ortiz, D.P., Yarranton, H.W., 2013. Molecular weight and density distributions of asphaltenes from crude oils. Energy and Fuels 27, 2474-2487. https://doi.org/10.1021/ef400142v

Benayada, B., Rahmani, Z., 1999. Anionic surfactant for the dispersion of the asphaltenes in porous media. Appl. Energy 64, 379-385. https://doi.org/https://doi.org/10.1016/S0306-2619(99)000483

Breen, P.J., 2001. Inhibition of asphaltene deposition in crude oil production systems. U.S. Patent 6,313,367B1.

Buckley, J.S., 1999. Predicting the Onset of Asphaltene Precipitation from Refractive Index Measurements. Energy \& Fuels 13, 328-332. https://doi.org/10.1021/ef980201c 
Campen, S., Di Mare, L., Smith, B., Wong, J.S.S., 2017. Determining the Kinetics of Asphaltene Adsorption from Toluene: A New Reaction-Diffusion Model. Energy and Fuels 31. https://doi.org/10.1021/acs.energyfuels.7b01374

Campen, S., Smith, B., Wong, J., 2018. Deposition of Asphaltene from Destabilized Dispersions in Heptane-Toluene. Energy \& Fuels. https://doi.org/10.1021/acs.energyfuels.8b01887

Castillo, J., Gutierrez, H., Ranaudo, M., Villarroel, O., 2010. Measurement of the refractive index of crude oil and asphaltene solutions: Onset flocculation determination. Energy and Fuels 24, 492495. https://doi.org/10.1021/ef900861d

Chang, C.-L., Fogler, H.S., 1994. Stabilization of Asphaltenes in Aliphatic Solvents Using Alkylbenzene-Derived Amphiphiles. 2. Study of the Asphaltene-Amphiphile Interactions and Structures Using Fourier Transform Infrared Spectroscopy and Small-Angle X-ray Scattering Techniques. Langmuir 10, 1758-1766. https://doi.org/10.1021/la00018a023

Creek, J.L., 2005. Freedom of Action in the State of Asphaltenes : Escape from Conventional Wisdom † 1212-1224. https://doi.org/10.1021/ef049778m

Darabi, H., Sepehrnoori, K., 2015. Modeling and Simulation of Near-Wellbore Asphaltene Remediation Using Asphaltene Dispersants. SPE Reserv. Simul. Symp. https://doi.org/10.2118/173284-MS

Dudášová, D., Silset, A., Sjöblom, J., 2008a. Quartz crystal microbalance monitoring of asphaltene adsorption/ deposition. J. Dispers. Sci. Technol. 29, 139-146.

https://doi.org/10.1080/01932690701688904

Dudášová, D., Simon, S., Hemmingsen, P. V., Sjöblom, J., 2008b. Study of asphaltenes adsorption onto different minerals and clays. Part 1. Experimental adsorption with UV depletion detection. Colloids Surfaces A Physicochem. Eng. Asp. 317, 1-9. https://doi.org/10.1016/j.colsurfa.2007.09.023

Dutta, A.K., Belfort, G., 2007. Adsorbed gels versus brushes: Viscoelastic differences. Langmuir 23, 3088-3094. https://doi.org/10.1021/la0624743

Elochukwu, O.H., Mahmud, H.K. Ben, 2015. An environmentally friendly solvent mix for asphaltene deposit removal. ARPN J. Eng. Appl. Sci. 10, 1055-10565.

Gon, S., Fouchard, D.M., 2016. Modi fi ed Asphaltene Capillary Deposition Unit: A Novel Approach to Inhibitor Screening. https://doi.org/10.1021/acs.energyfuels.5b02185

Goual, L., Firoozabadi, A., 2004. Effect of Resins and DBSA on Asphaltene 50.

Goual, L., Sedghi, M., 2015. Role of ion-pair interactions on asphaltene stabilization by 
alkylbenzenesulfonic acids. J. Colloid Interface Sci. 440, 23-31.

https://doi.org/10.1016/j.jcis.2014.10.043

Goual, L., Sedghi, M., Wang, X., Zhu, Z., 2014. Asphaltene aggregation and impact of alkylphenols. Langmuir 30, 5394-5403. https://doi.org/10.1021/la500615k

Guo, B., Song, S., Chacko, J., Ghalambor, A., 2005. Pigging Operations, in: Offshore Pipelines. pp. 215-233. https://doi.org/10.1016/b978-075067847-6/50073-1

Hashmi, S.M., Firoozabadi, A., 2013a. Self-assembly of resins and asphaltenes facilitates asphaltene dissolution by an organic acid. J. Colloid Interface Sci. 394, 115-123. https://doi.org/10.1016/j.jcis.2012.11.069

Hashmi, S.M., Firoozabadi, A., 2013b. Asphaltene deposition in metal pipes: Efficient inhibition and removal by different surfactants. Proc. - SPE Annu. Tech. Conf. Exhib. 5, 3858-3871.

Hashmi, S.M., Firoozabadi, A., 2012. Controlling nonpolar colloidal asphaltene aggregation by electrostatic repulsion. Energy and Fuels 26, 4438-4444. https://doi.org/10.1021/ef3005702

Hashmi, S.M., Loewenberg, M., Firoozabadi, A., 2015. Colloidal asphaltene deposition in laminar pipe flow: Flow rate and parametric effects. Phys. Fluids 27. https://doi.org/10.1063/1.4927221

Hashmi, S.M., Quintiliano, L.A., Firoozabadi, A., 2010. Polymeric dispersants delay sedimentation in colloidal asphaltene suspensions. Langmuir 26, 8021-8029. https://doi.org/10.1021/la9049204

Hashmi, S.M., Zhong, K.X., Firoozabadi, A., 2012. Acid-base chemistry enables reversible colloid-tosolution transition of asphaltenes in non-polar systems. Soft Matter 8, 8778-8785. https://doi.org/10.1039/c2sm26003d

Higaki, Y., Hatae, K., Ishikawa, T., Takanohashi, T., Hayashi, J., Takahara, A., 2014. Adsorption and Desorption Behavior of Asphaltene on Polymer-Brush-Immobilized Surfaces. ACS Appl. Mater. Interfaces 6, 20385-20389. https://doi.org/10.1021/am505904b

Hoepfner, M.P., Limsakoune, V., Chuenmeechao, V., Maqbool, T., Scott Fogler, H., 2013. A fundamental study of asphaltene deposition. Energy and Fuels 27, 725-735. https://doi.org/10.1021/ef3017392

Höök, F., Kasemo, B., Nylander, T., Fant, C., Sott, K., Elwing, H., 2001. Variations in coupled water, viscoelastic properties, and film thickness of a Mefp-1 protein film during adsorption and crosslinking: A quartz crystal microbalance with dissipation monitoring, ellipsometry, and surface plasmon resonance study. Anal. Chem. 73, 5796-5804. https://doi.org/10.1021/ac0106501

Ibrahim, H.H., Idem, R.O., 2004. Interrelationships between Asphaltene Precipitation Inhibitor Effectiveness, Asphaltenes Characteristics, and Precipitation Behavior during n-Heptane (Light 
Paraffin Hydrocarbon)-Induced Asphaltene Precipitation. Energy \& Fuels 18, 1038-1048. https://doi.org/10.1021/ef0340460

Jamaluddin, A.K.M., Nazarko, T.W., 1995. Process for removing and preventing near-wellbore damage due to asphaltene precipitation. U.S. Patent 5,425,422.

Jennings, D.W., Chao, K.P., Kim, J., 2018. Asphaltene inhibitor testing: Comparison between a high pressure live-fluid deposition and ambient pressure dead-oil asphaltene stability method. Proc. Annu. Offshore Technol. Conf. https://doi.org/10.4043/28650-MS

Joonaki, E., Burgass, R., Hassanpouryouzband, A., Tohidi, B., 2018. Comparison of Experimental Techniques for Evaluation of Chemistries against Asphaltene Aggregation and Deposition: New Application of High-Pressure and High-Temperature Quartz Crystal Microbalance. Energy and Fuels 32, 2712-2721. https://doi.org/10.1021/acs.energyfuels.7b02773

Kaimaki, D.-M., Smith, B.E., Durkan, C., 2018. On the use of nanomechanical atomic force microscopy to characterise oil-exposed surfaces. RSC Adv. 8, 6680-6689. https://doi.org/10.1039/C7RA12209H

Kawanaka, S., Leontaritis, K.J., Park, S.J., Mansoori, G.A., 1989. Thermodynamic and Colloidal Models of Asphaltene Flocculation, in: Oil-Field Chemistry, ACS Symposium Series. American Chemical Society, pp. 443-458. https://doi.org/10.1021/bk-1989-0396.ch024

Keller, C.A., Kasemo, B., 1998. Surface specific kinetics of lipid vesicle adsorption measured with a quartz crystal microbalance. Biophys. J. 75, 1397-1402. https://doi.org/10.1016/S00063495(98)74057-3

Khvostichenko, D.S., Andersen, S.I., 2010. Electrodeposition of Asphaltenes. 2. Effect of Resins and Additives. Energy \& Fuels 24, 2327-2336. https://doi.org/10.1021/ef900970j

Kor, P., Kharrat, R., 2016. Modeling of asphaltene particle deposition from turbulent oil flow in tubing: Model validation and a parametric study. Petroleum 2, 393-398. https://doi.org/10.1016/j.petIm.2016.08.010

Kurup, A.S., Vargas, F.M., Wang, J., Buckley, J., Creek, J.L., Subramani J., H., Chapman, W.G., 2011. Development and Application of an Asphaltene Deposition Tool (ADEPT) for Well Bores. Energy \& Fuels 25, 4506-4516. https://doi.org/10.1021/ef200785v

León, O., Rogel, E., Urbina, A., Andújar, A., Lucas, A., 1999. Study of the adsorption of alkyl benzene-derived amphiphiles on asphaltene particles. Langmuir 15, 7653-7657. https://doi.org/10.1021/la9812370

Leontaritis, K.J., Amaefule, J.O., Charles, R.E., 1994. A systematic approach for the prevention and treatment of formation damage caused by asphaltene deposition. SPE Prod. Facil. 9, 157-164. 
https://doi.org/10.2118/23810-PA

Leontaritis, K.J., Mansoori, G.A., 1987. Asphaltene Flocculation During Oil Production and Processing: A Thermodynamic Colloidal Model. Spe 149-158. https://doi.org/10.2118/16258-MS

Lin, Y.-J., He, P., Tavakkoli, M., Mathew, N.T., Fatt, Y.Y., Chai, J.C., Goharzadeh, A., Vargas, F.M., Biswal, S.L., 2017. Characterizing Asphaltene Deposition in the Presence of Chemical Dispersants in Porous Media Micromodels. Energy \& Fuels 31, 11660-11668. https://doi.org/10.1021/acs.energyfuels.7b01827

Lin, Y.-J., He, P., Tavakkoli, M., Mathew, N.T., Fatt, Y.Y., Chai, J.C., Goharzadeh, A., Vargas, F.M., Biswal, S.L., 2016. Examining Asphaltene Solubility on Deposition in Model Porous Media. Langmuir 32, 8729-8734. https://doi.org/10.1021/acs.langmuir.6b02376

Liu, S.X., Kim, J.T., 2009. Application of Kevin—Voigt Model in Quantifying Whey Protein Adsorption on Polyethersulfone Using QCM-D. J. Lab. Autom. 14, 213-220. https://doi.org/10.1016/j.jala.2009.01.003

Liu, Z.Y., Wei, N., Wang, C., Zhou, H., Zhang, Lei, Liao, Q., Zhang, Lu, 2015. Interfacial assignment of branched-alkyl benzene sulfonates: A molecular simulation. AIP Adv. 5. https://doi.org/10.1063/1.4935339

Madhi, M., Kharrat, R., Hamoule, T., 2018. Screening of inhibitors for remediation of asphaltene deposits: Experimental and modeling study. Petroleum 4, 168-177. https://doi.org/https://doi.org/10.1016/j.petlm.2017.08.001

Manek, M.B., Sawhney, K.N., 1996. Alkyl Sustituted Phenol-Polyethylenepolyamine-Formaldehyde Resins as Asphaltene Dispersants. U.S. Patent 5,494,607.

Mansoori, G.A., 2010. Remediation of asphaltene and other heavy organic deposits in oil wells and in pipelines. SOCAR Proc. 2010, 12-23. https://doi.org/10.5510/OGP20100400039

Mansur, C.R.E., De Melo, A.R., Lucas, E.F., 2012. Determination of asphaltene particle size: Influence of flocculant, additive, and temperature. Energy and Fuels 26, 4988-4994. https://doi.org/10.1021/ef300365x

Marcano, F., Moura, L.G.M., Cardoso, F.M.R., Rosa, P.T.V., 2015. Evaluation of the chemical additive effect on asphaltene aggregation in dead oils: A comparative study between ultraviolet-visible and near-infrared-laser light scattering techniques. Energy and Fuels 29, 2813-2822. https://doi.org/10.1021/ef502071t

Marques, L.C.C., Pereira, J.O., Marques, V.S., Lucas, E.F., Mansur, C.R.E., 2012. A Study of Asphaltene-Resin Interactions 23, 1880-1888. 
Mohammadi, S., Rashidi, F., Mousavi-Dehghani, S.A., Ghazanfari, M.H., 2016. On the effect of temperature on precipitation and aggregation of asphaltenes in light live oils. Can. J. Chem. Eng. 94, 1820-1829. https://doi.org/10.1002/cjce.22555

Mullins, O.C., 2011. The Asphaltenes. Annu. Rev. Anal. Chem. 4, 393-418. https://doi.org/10.1146/annurev-anchem-061010-113849

Notley, S.M., Eriksson, M., Wågberg, L., 2005. Visco-elastic and adhesive properties of adsorbed polyelectrolyte multilayers determined in situ with QCM-D and AFM measurements. J. Colloid Interface Sci. 292, 29-37. https://doi.org/10.1016/j.jcis.2005.05.057

Paes, D.M., Ribeiro, P.R., Shirdel, M., Sepehrnoori, K., 2015. Study of asphaltene deposition in wellbores during turbulent flow. J. Pet. Sci. Eng. 129, 77-87. https://doi.org/10.1016/j.petrol.2015.02.010

Pfeiffer, J.P., Saal, R.N.J., 1939. Asphaltic bitumen as colloid system. Sixt. Colloid. Symp. 139-149. https://doi.org/10.1021/j150398a001

Porte, G., Zhou, H., Lazzeri, V., 2003. Reversible description of asphaltene colloidal association and precipitation. Langmuir 19, 40-47. https://doi.org/10.1021/la0260279

Pradilla, D., Subramanian, S., Simon, S., Sjöblom, J., Beurroies, I., Denoyel, R., 2016. Microcalorimetry Study of the Adsorption of Asphaltenes and Asphaltene Model Compounds at the Liquid-Solid Surface. Langmuir 32, 7294-7305. https://doi.org/10.1021/acs.langmuir.6b00816

Richter, R., Mukhopadhyay, A., Brisson, A., 2003. Pathways of lipid vesicle deposition on solid surfaces: a combined QCM-D and AFM study. Biophys. J. 85, 3035-47. https://doi.org/10.1016/S0006-3495(03)74722-5

Rodahl, M., Höök, F., Krozer, A., Brzezinski, P., Kasemo, B., 1995. Quartz crystal microbalance setup for frequency and Q-factor measurements in gaseous and liquid environments. Rev. Sci. Instrum. 66, 3924-3930. https://doi.org/10.1063/1.1145396

Rogel, E., 2011. Effect of Inhibitors on Asphaltene Aggregation: A Theoretical Framework. Energy \& Fuels 25, 472-481. https://doi.org/10.1021/ef100912b

Rogel, E., León, O., 2001. Study of the adsorption of alkyl-benzene-derived amphiphiles on an asphaltene surface using molecular dynamics simulations. Energy and Fuels 15, 1077-1086. https://doi.org/10.1021/ef000152f

Rogel, E., Ovalles, C., Moir, M., 2010. Asphaltene Stability in Crude Oils and Petroleum Materials by Solubility Profile Analysis 4369-4374. https://doi.org/10.1021/ef100478y 
Ruiz-morales, Y., Mullins, O.C., 2007. Polycyclic Aromatic Hydrocarbons of Asphaltenes Analyzed by Molecular Orbital Calculations with Optical Spectroscopy 256-265. https://doi.org/10.1021/ef060250m

Schuler, B., Meyer, G., Peña, D., Mullins, O.C., Gross, L., 2015. Unraveling the Molecular Structures of Asphaltenes by Atomic Force Microscopy. J. Am. Chem. Soc. 137, 9870-9876. https://doi.org/10.1021/jacs.5b04056

Seyyedbagheri, H., Mirzayi, B., 2017. Eulerian Model To Predict Asphaltene Deposition Process in Turbulent Oil Transport Pipelines. https://doi.org/10.1021/acs.energyfuels.7b01273

Smith, D.F., Klein, G.C., Yen, A.T., Squicciarini, M.P., Rodgers, R.P., Marshall, A.G., Newport, C., Uni, V., Place, U. V, News, N., 2008. Crude Oil Polar Chemical Composition Derived from FT ICR Mass Spectrometry Accounts for Asphaltene Inhibitor Specificity 36, 3112-3117.

Soorghali, F., Zolghadr, A., Ayatollahi, S., 2014. E ff ect of Resins on Asphaltene Deposition and the Changes of Surface Properties at Di ff erent Pressures: A Microstructure Study 2415-2421. https://doi.org/10.1021/ef500020n

Speight, J.G., 2004. Petroleum Asphaltenes Asphaltenes, Resins and the Structure of Petroleum 59, 467-477.

Subramanian, S., Buscetti, L., Simon, S., Sacré, M., Sjöblom, J., 2018a. Influence of Fatty-Alkylamine Amphiphile on the Asphaltene Adsorption/Deposition at the Solid/Liquid Interface under Precipitating Conditions. Energy and Fuels 32, 4772-4782.

https://doi.org/10.1021/acs.energyfuels.8b00059

Subramanian, S., Simon, S., Sjöblom, J., 2018b. Interaction between asphaltenes and fattyalkylamine inhibitor in bulk solution. J. Dispers. Sci. Technol. 39, 163-173. https://doi.org/10.1080/01932691.2017.1304221

Sung, C.A., Tavakkoli, M., Chen, A., Vargas, F.M., 2016. Prevention and control of corrosion-induced asphaltene deposition. Proc. Annu. Offshore Technol. Conf. 2, 1589-1603.

Tavakkoli, M., Grimes, M.R., Liu, X., Garcia, C.K., Correa, S.C., Cox, Q.J., Vargas, F.M., 2015. Indirect method: A novel technique for experimental determination of asphaltene precipitation. Energy and Fuels 29, 2890-2900. https://doi.org/10.1021/ef502188u

Tavakkoli, M., Panuganti, S.R., Vargas, F.M., Taghikhani, V., Pishvaie, M.R., Chapman, W.G., 2014. Asphaltene Deposition in Different Depositing Environments: Part 1. Model Oil. Energy \& Fuels 28, 1617-1628. https://doi.org/10.1021/ef401857t

Taylor, S.D., Czarnecki, J., Masliyah, J., 2001. Refractive index measurements of diluted bitumen solutions. Fuel 80, 2013-2018. https://doi.org/https://doi.org/10.1016/S0016-2361(01)00087-4 
Trbovich, M.G., King, G.E., 1991. Asphaltene Deposit Removal: Long-Lasting Treatment With a CoSolvent. SPE Int. Symp. Oilf. Chem. https://doi.org/10.2118/21038-MS

Trimble, M.I., Fleming, M.A., Andrew, B.L., Tomusiak, G.A., DiGiacinto, P.M., Heymans, L.M., 2008. Method for removing asphaltene deposits. U.S. Patent 2008/0020949A1.

Turgman-Cohen, S., Fischer, D.A., Kilpatrick, P.K., Genzer, J., 2009a. Asphaltene Adsorption onto Self-Assembled Monolayers of Alkyltrichlorosilanes of Varying Chain Length. ACS Appl. Mater. Interfaces 1, 1347-1357. https://doi.org/10.1021/am900203u

Turgman-Cohen, S., Smith, M.B., Fischer, D.A., Kilpatrick, P.K., Genzer, J., 2009b. Asphaltene Adsorption onto Self-Assembled Monolayers of Mixed Aromatic and Aliphatic Trichlorosilanes. Langmuir 25, 6260-6269. https://doi.org/10.1021/la9000895

Vargas, F.P., 2016. Advanced strategies for mitigation of asphaltene deposition, in: 2nd Annual Production Chemicals Optimization Conference, Unconventional Oil and Gas. Houston, Texas, USA.

Vilas Bôas Fávero, C., Hanpan, A., Phichphimok, P., Binabdullah, K., Fogler, H.S., 2016. Mechanistic Investigation of Asphaltene Deposition. Energy \& Fuels 30, 8915-8921. https://doi.org/10.1021/acs.energyfuels.6b01289

Wang, J., Li, C., Zhang, L., Que, G., Li, Z., 2009. The properties of asphaltenes and their interaction with amphiphiles. Energy and Fuels 23, 3625-3631. https://doi.org/10.1021/ef801148y

Wang, M.M., Sungail, C.M., Chen, X., Kaufman, J.H., 2017. Asphaltene Inhibition. U.S. Patent 2017/0306215 A1.

Wei, D., Orlandi, E., Simon, S., Sjöblom, J., Suurkuusk, M., 2015. Interactions between asphaltenes and alkylbenzene-derived inhibitors investigated by isothermal titration calorimetry. J. Therm. Anal. Calorim. 120, 1835-1846. https://doi.org/10.1007/s10973-015-4542-z

Wylde, J.J., 2011. Chemical assisted pipeline cleaning for pigging operations. Pipeline Gas J. 238.

Yarranton, H.W., Ortiz, D.P., Barrera, D.M., Baydak, E.N., Barré, L., Frot, D., Eyssautier, J., Zeng, H., Xu, Z., Dechaine, G., Becerra, M., Shaw, J.M., McKenna, A.M., Mapolelo, M.M., Bohne, C., Yang, Z., Oake, J., 2013. On the size distribution of self-associated asphaltenes. Energy and Fuels 27, 5083-5106. https://doi.org/10.1021/ef400729w

Yudin, I.K., Nikolaenko, G.L., Gorodetskii, E.E., Kosov, V.I., Melikyan, V.R., Markhashov, E.L., Frot, D., Briolant, Y., 1998. Mechanisms of asphaltene aggregation in toluene-heptane mixtures. J. Pet. Sci. Eng. 20, 297-301. https://doi.org/10.1016/S0920-4105(98)00033-3 
Tables

Table 1. Concentration of Inhibitor $\mathrm{A}$ in heptane-toluene in $\mathrm{gL}^{-1}$ and $\mathrm{ppm}$

\begin{tabular}{|l|r|r|r|r|r|r|}
\hline Concentration $\left(\mathrm{gL}^{-1}\right)$ & \multicolumn{5}{|c|}{ Concentration of Inhibitor A in heptane-toluene $(\mathrm{ppm})$} \\
\hline & $\begin{array}{r}0 \text { vol\% } \\
\text { heptane }\end{array}$ & $\begin{array}{r}50 \text { vol\% } \\
\text { heptane }\end{array}$ & $\begin{array}{r}60 \text { vol\% } \\
\text { heptane }\end{array}$ & $\begin{array}{r}70 \text { vol\% } \\
\text { heptane }\end{array}$ & $\begin{array}{r}80 \text { vol\% } \\
\text { heptane }\end{array}$ & $\begin{array}{r}90 \text { vol\% } \\
\text { heptane }\end{array}$ \\
\hline 0.001 & 1.15 & 1.29 & 1.32 & 1.36 & 1.39 & 1.43 \\
\hline 0.01 & 11.5 & 11.29 & 13.2 & 13.6 & 13.9 & 14.3 \\
\hline 0.1 & 115 & 129 & 132 & 136 & 139 & 143 \\
\hline 1 & 1150 & 1290 & 1320 & 1360 & 1390 & 1430 \\
\hline 10 & 11500 & 12900 & 13200 & 13600 & 13900 & 14300 \\
\hline 100 & 115000 & 129000 & 132000 & 136000 & 139000 & 143000 \\
\hline
\end{tabular}

Table 2. Adsorption of Inhibitor A onto gold from toluene

\begin{tabular}{|l|r|r|}
\hline $\begin{array}{l}\text { Concentration of } \\
\text { Inhibitor A }\left(\mathrm{gL}^{-1}\right)\end{array}$ & $\begin{array}{r}\text { Adsorbed amount } \\
\text { before toluene- } \\
\text { rinsing }\left(\mathrm{ngcm}^{-2}\right)\end{array}$ & $\begin{array}{r}\text { Adsorbed amount } \\
\text { after toluene-rinsing } \\
\left(\mathrm{ngcm}^{-2}\right)\end{array}$ \\
\hline 0.01 & 19 & 17 \\
\hline 0.1 & 175 & 155 \\
\hline 1 & 362 & 339 \\
\hline 10 & 366 & 339 \\
\hline 100 & 360 & 344 \\
\hline
\end{tabular}

Table 3. Summary of observed behaviours for Inhibitor A

\begin{tabular}{|c|c|c|}
\hline Property & In Toluene & In heptane-toluene \\
\hline Anti-agglomerant & $\begin{array}{l}\text { No measurable effect } \\
\text { (asphaltene is well-dispersed in } \\
\text { toluene) }\end{array}$ & $\begin{array}{l}\checkmark \text { Inhibitor prevents flocculation of } \\
\text { asphaltene, aggregates of } \\
\text { intermediate } \sim 180 \mathrm{~nm} \text { size form } \\
\text { instead }\end{array}$ \\
\hline Barrier-type coating & $\begin{array}{l}\checkmark \text { Pre-adsorbed inhibitor } \\
\text { monolayer prevents asphaltene } \\
\text { adsorption }\end{array}$ & $\begin{array}{l}\text { Destabilised asphaltene deposits } \\
\text { onto pre-adsorbed inhibitor } \\
\text { monolayer }\end{array}$ \\
\hline Remedial use & $\begin{array}{l}\checkmark \text { Inhibitor displaces pre-adsorbed } \\
\text { asphaltene monolayer }\end{array}$ & $\begin{array}{l}\text { x Inhibitor cannot displace/remove } \\
\text { a thick asphaltene deposit, but } \\
\text { some swelling of the film occurs }\end{array}$ \\
\hline $\begin{array}{l}\text { Co-deposition from } \\
\text { pre-mixed } \\
\text { asphaltene/inhibitor }\end{array}$ & $\begin{array}{l}\checkmark \text { Asphaltene adsorbs initially, but } \\
\text { is displaced by inhibitor (inhibitor } \\
\text { adsorbs more slowly than } \\
\text { asphaltene) }\end{array}$ & $\begin{array}{l}\checkmark \text { At low heptane vol\%, inhibitor } \\
\text { slows the rate of deposition } \\
\times \quad \text { At high heptane vol\%, inhibitor is } \\
\text { only marginally effective at } \\
\text { reducing deposition } \\
\times \quad \text { At high heptane vol\%, inhibitor } \\
\text { over-treatment (above } \\
\text { recommended dose) increases } \\
\text { deposition } \\
\text { Inhibitor changes nature of } \\
\text { deposit from floc to small particle }\end{array}$ \\
\hline
\end{tabular}




\section{Figures}

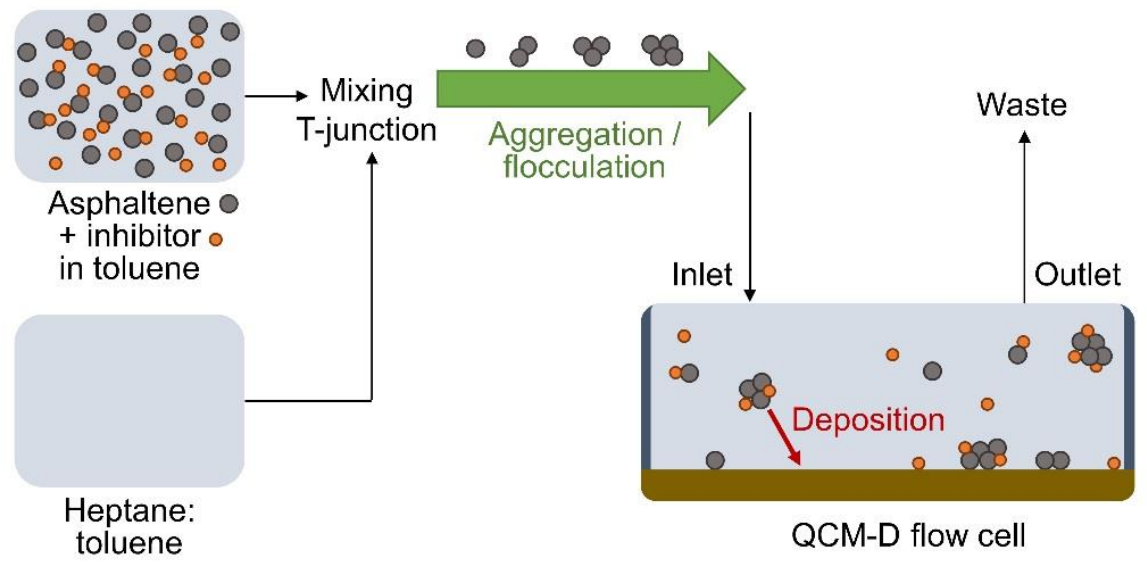

Figure 1. Schematic showing method for monitoring efficacy of inhibitor for preventing asphaltene deposition from destabilised dispersions in heptane-toluene by QCM-D using 2-pump system. Asphaltenes are destabilised at point of mixing with heptane and aggregation/flocculation can occur before, inside and after QCM flow cell.

(a)

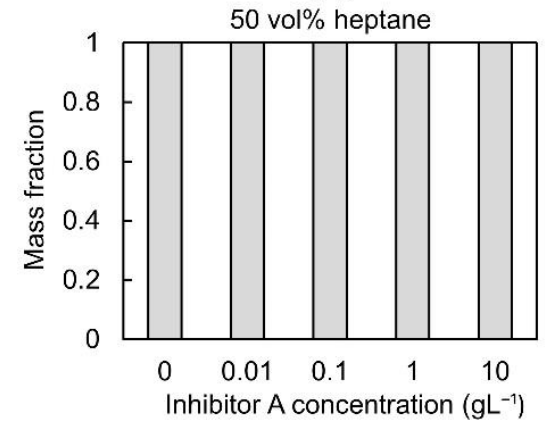

(d)

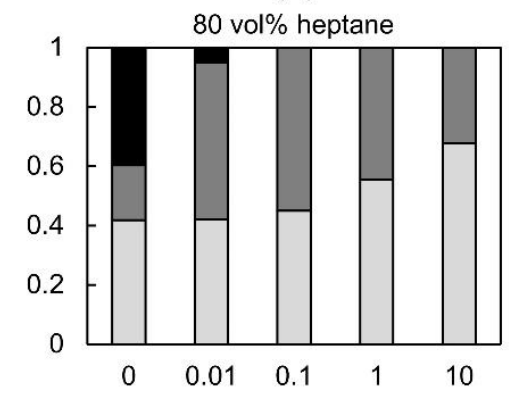

(b)

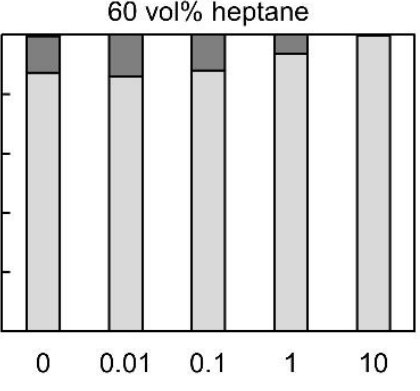

(e)

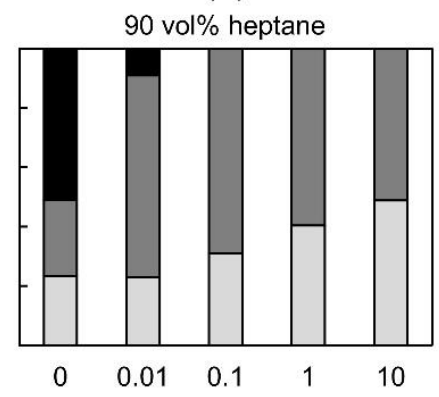

(c)

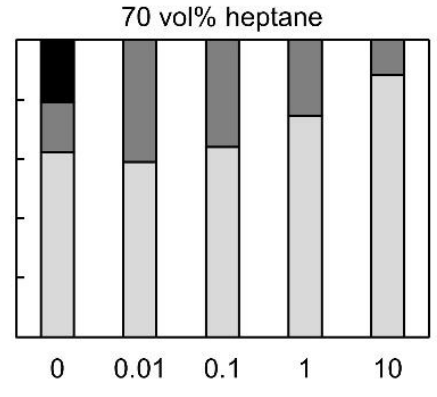

- $\mathrm{d} \geq 1000 \mathrm{~nm}$

$\square 100 \leq \mathrm{d}<1000 \mathrm{~nm}$

$\square \mathrm{d}<100 \mathrm{~nm}$

Figure 2. Particle size distribution at destabilisation time of 10 minutes determined by centrifugationUV-vis spectroscopy for $0.1 \mathrm{gL}^{-1}$ asphaltene with increasing Inhibitor A concentration in heptanetoluene at (a) 0 , (b) 60, (c) 70, (d) 80 and (e) 90 vol\% heptane 

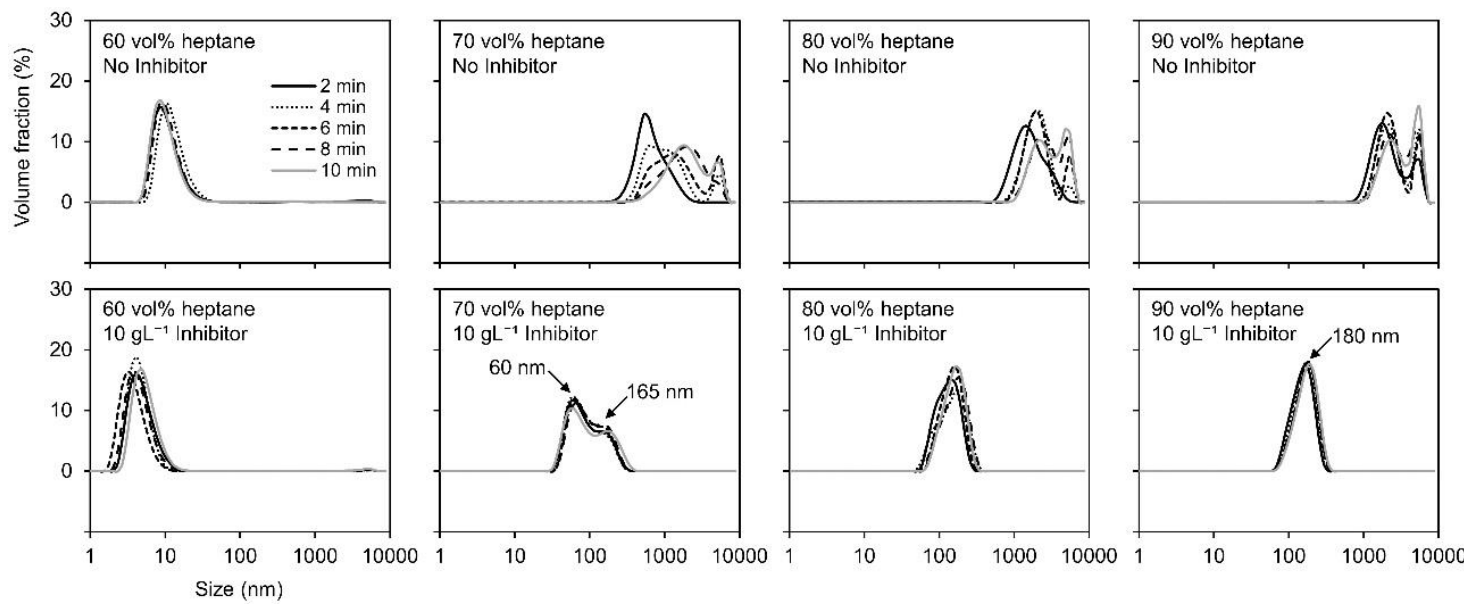

Figure 3. Particle size distribution determined by DLS for $0.1 \mathrm{gL}^{-1}$ asphaltene in heptane-toluene with no inhibitor (top row) and $10 \mathrm{gL}^{-1}$ Inhibitor A (bottom row) at destabilisation times of 2, 4, 6, 8 and 10 $\min$
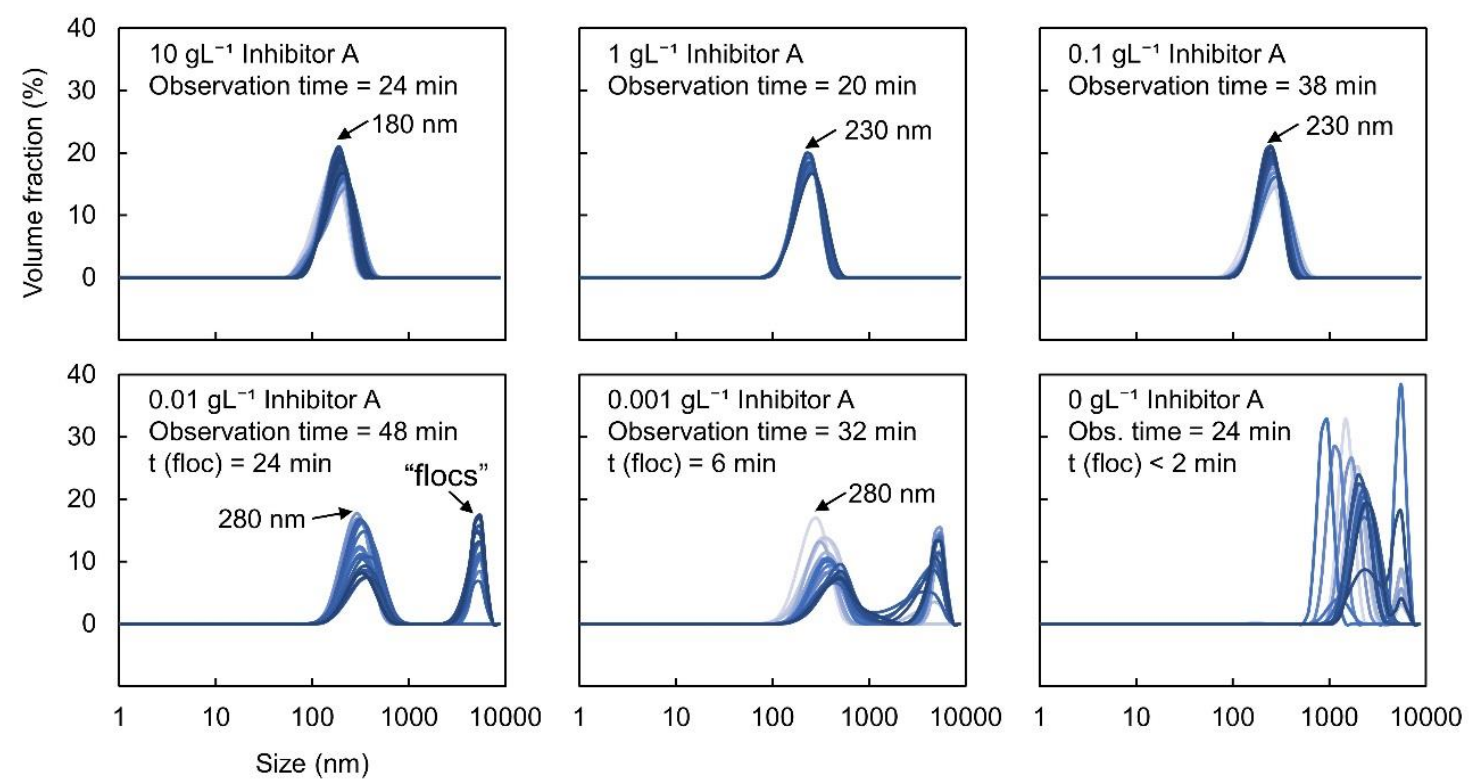

Figure 4. Particle size distribution determined by DLS for $0.1 \mathrm{gL}^{-1}$ asphaltene in 90 vol\% heptane at different Inhibitor A concentrations, lines show measuemnts at different times from first (light blue) to last (dark blue), observation time is the the total time for which measurments were taken, $t$ (floc) is the time at which particles $>1000 \mathrm{~nm}$ are first observed 

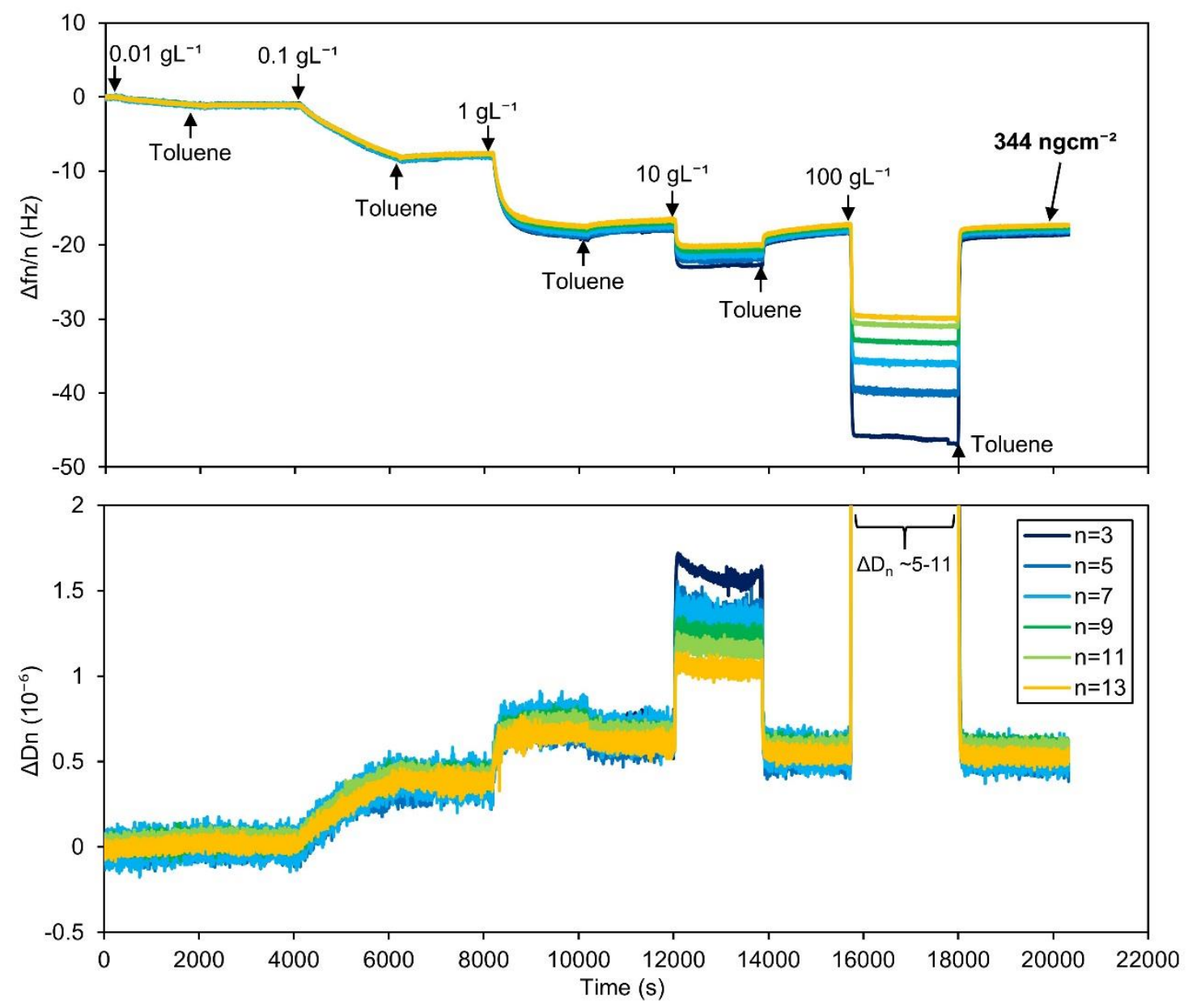

Figure 5. QCM-D frequency (top) and dissipation shifts (bottom) during adsorption of Inhibitor A onto gold from solution in toluene at increasing concentration. After each period of asphaltene inhibitor flow, the surface was rinsed with toluene. The experiment was undertaken at $20^{\circ} \mathrm{C}, 6 \mu \mathrm{Ls}^{-1}$ flow rate, and results from different overtones ( $\mathrm{n}$ ) are plotted. 


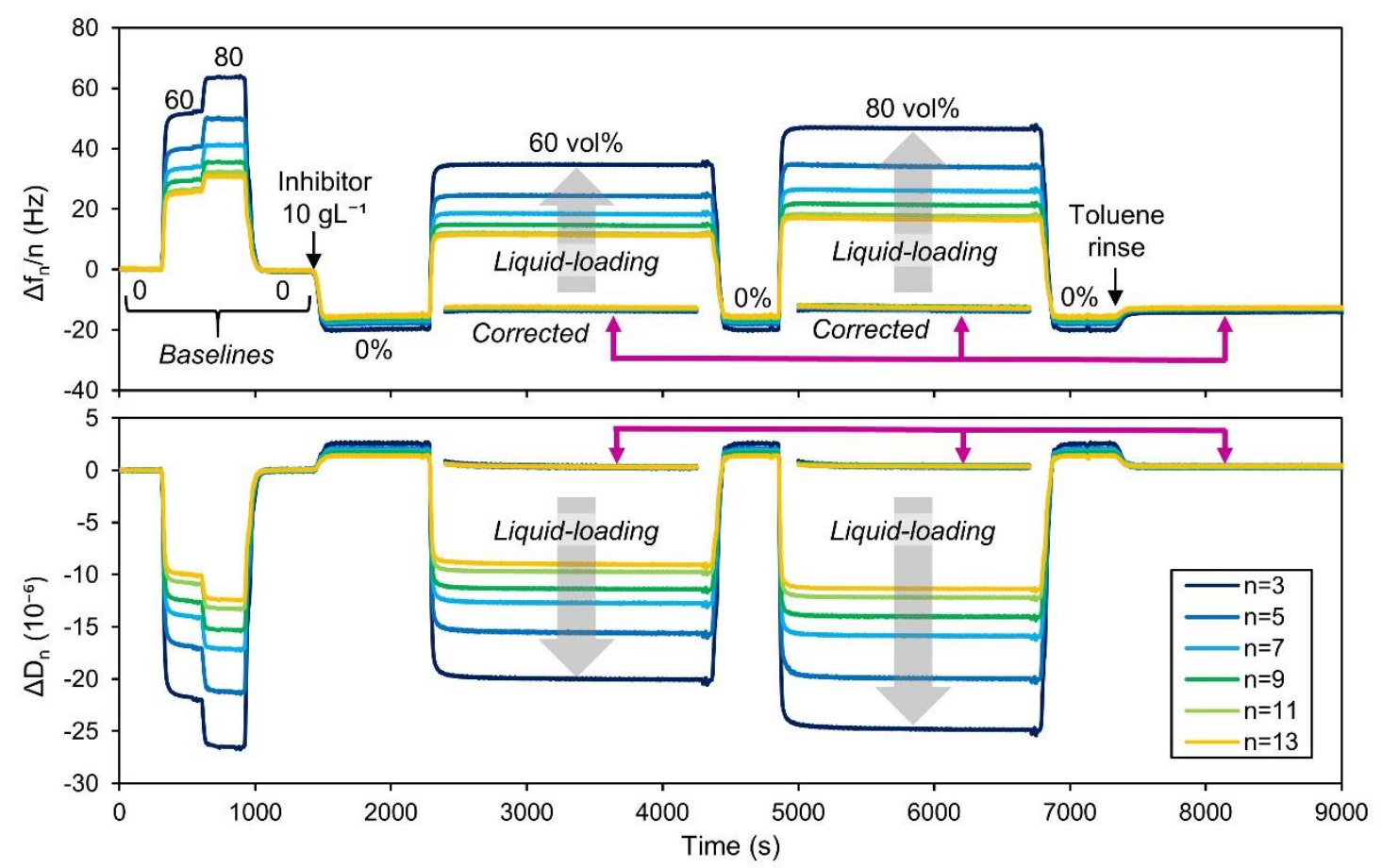

Figure 6. QCM-D frequency (top) and dissipation shifts (bottom) during adsorption of Inhibitor A onto gold from solution in heptane-toluene, mass is unchanged in 60 and 80 vol\% heptane after correcting for liquid-loading (see pink arrows), $20^{\circ} \mathrm{C}, 20 \mu \mathrm{Ls}^{-1}$ flow rate
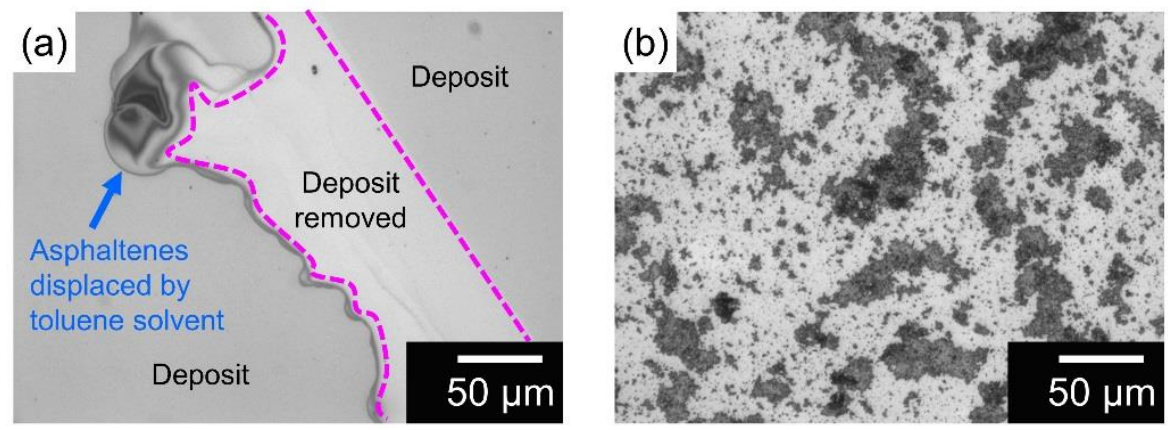

Figure 7. Optical micrographs of asphaltene deposits from (a) 60 and (b) 80 vol\% heptane on a goldcoated QCM-D sensor 
(a)

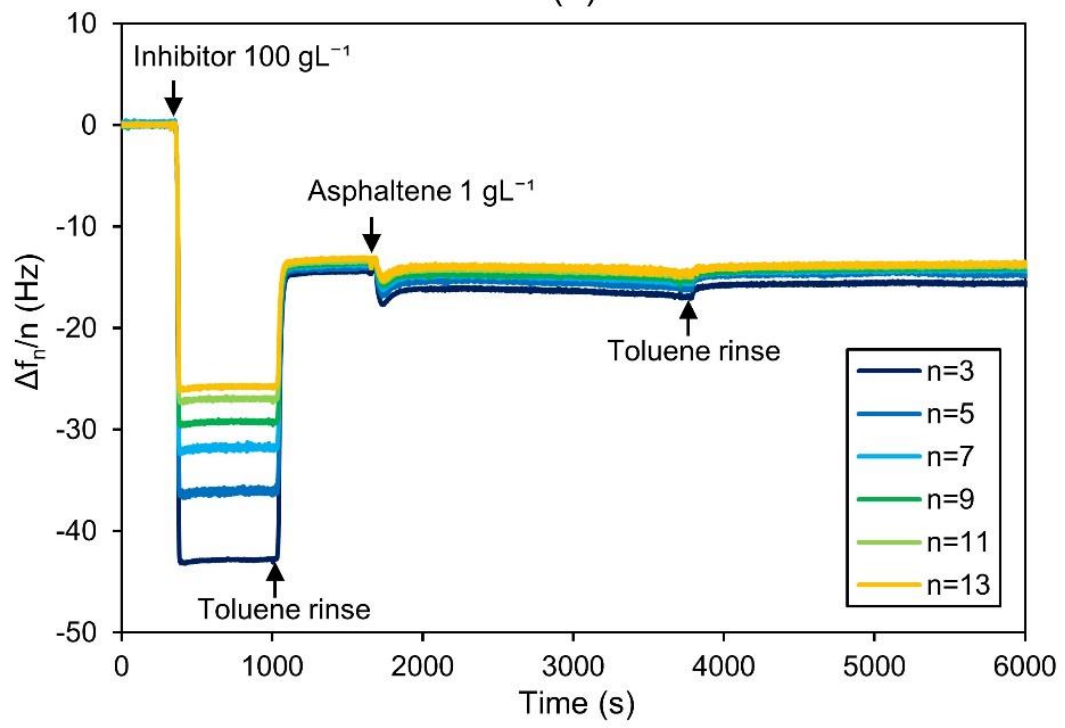

(b)

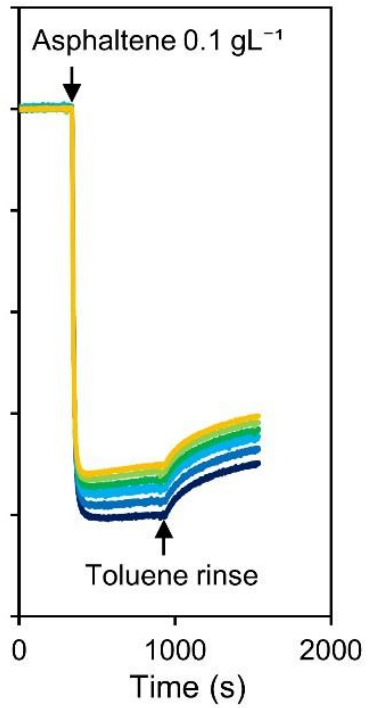

Figure 8. Efficacy of Inhibitor A as a barrier-type coating in toluene, QCM-D frequency shifts showing (a) pre-adsorbed inhibitor film prevents asphaltene adsorption and (b) adsorption of asphaltene onto clean gold surface 

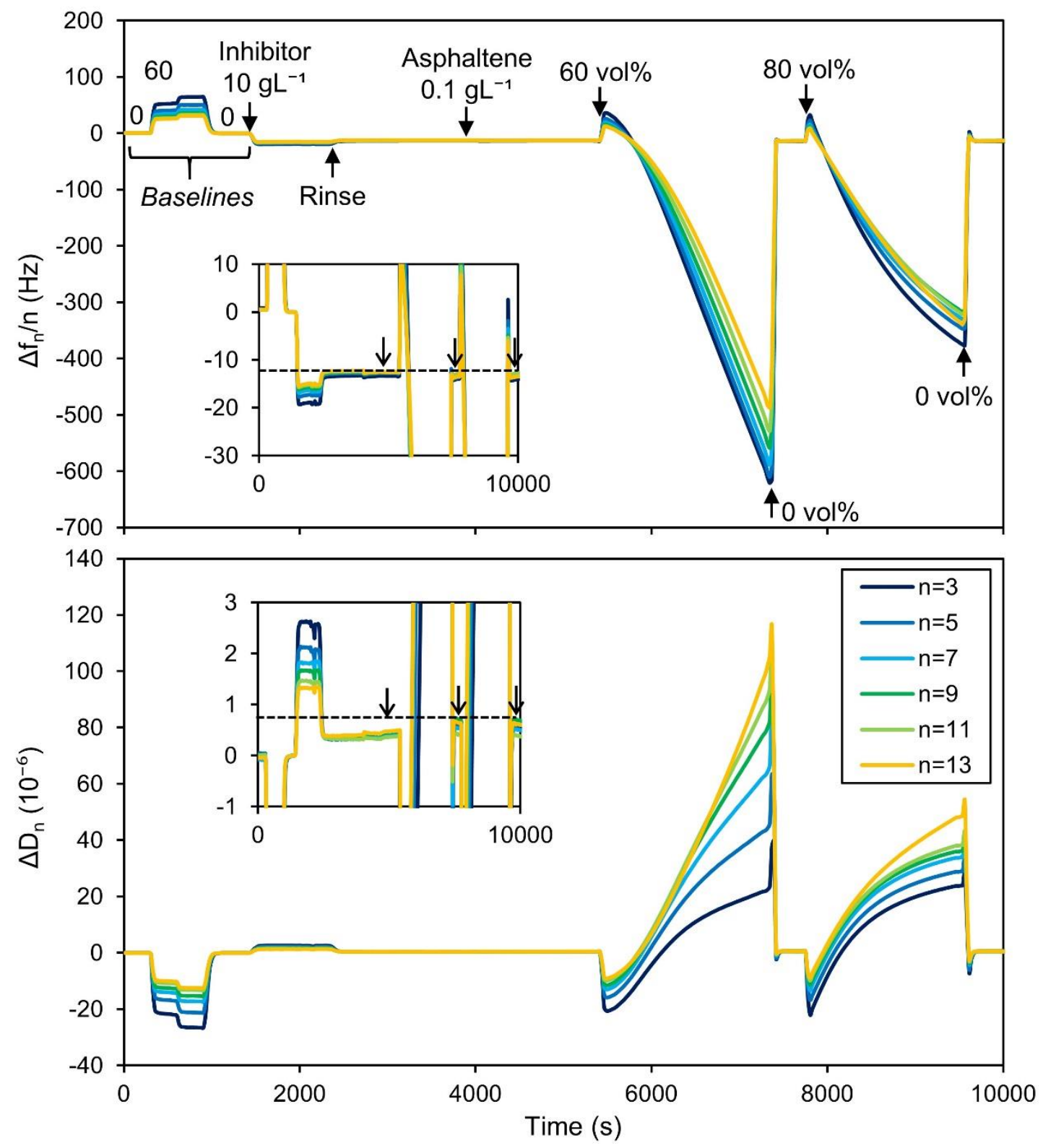

Figure 9. Efficacy of Inhibitor A as a barrier-type coating in heptane-toluene, QCM-D frequency (top) and dissipation shifts (bottom) showing asphaltene deposits from 60 and 80 vol\% heptane onto preformed inhibitor monolayer, insets compare shifts observed in 0 vol\% heptane 
(a)
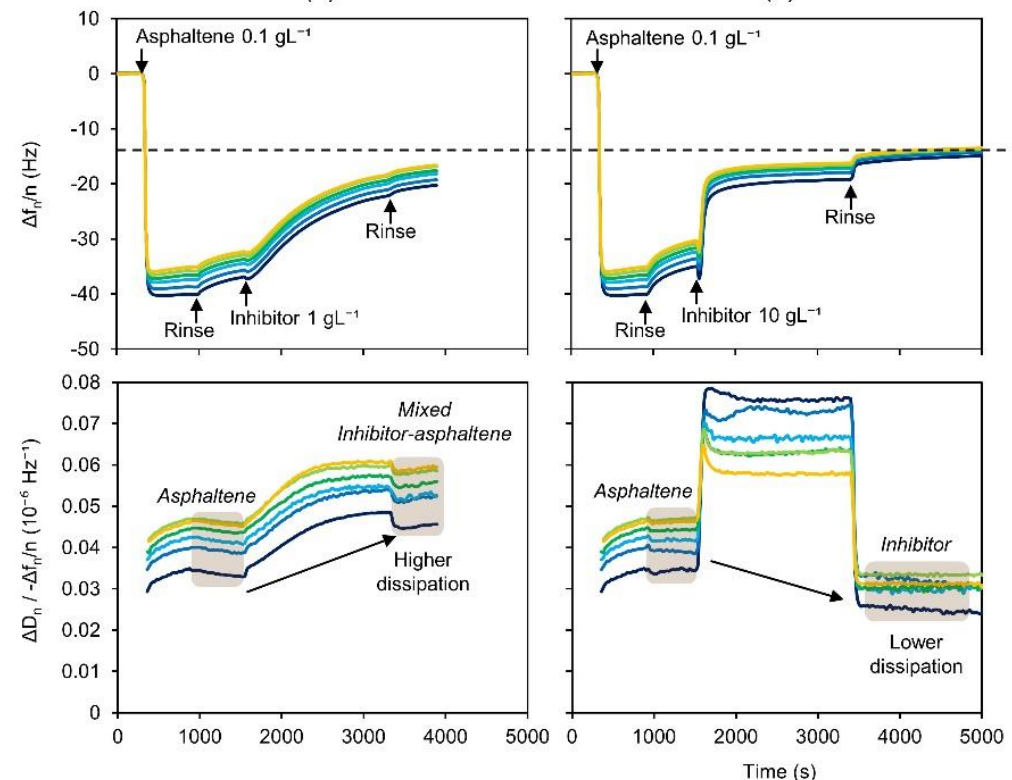

(c)
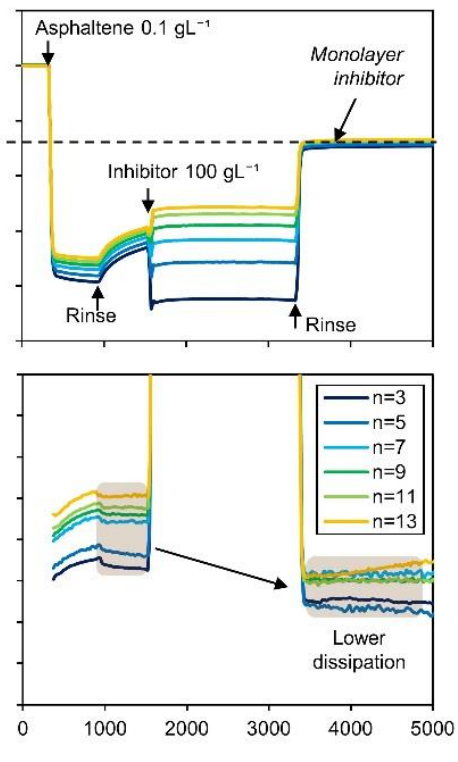

Figure 10. Use of Inhibitor A to remove pre-deposited asphaltene films in toluene, QCM-D frequency (top) and relative dissipation (bottom) for inhibitor concentrations of (a) 1, (b) 10 and (c) $100 \mathrm{gL}^{-1}$, $20^{\circ} \mathrm{C}, 6 \mu \mathrm{Ls}^{-1}$ flow rate 


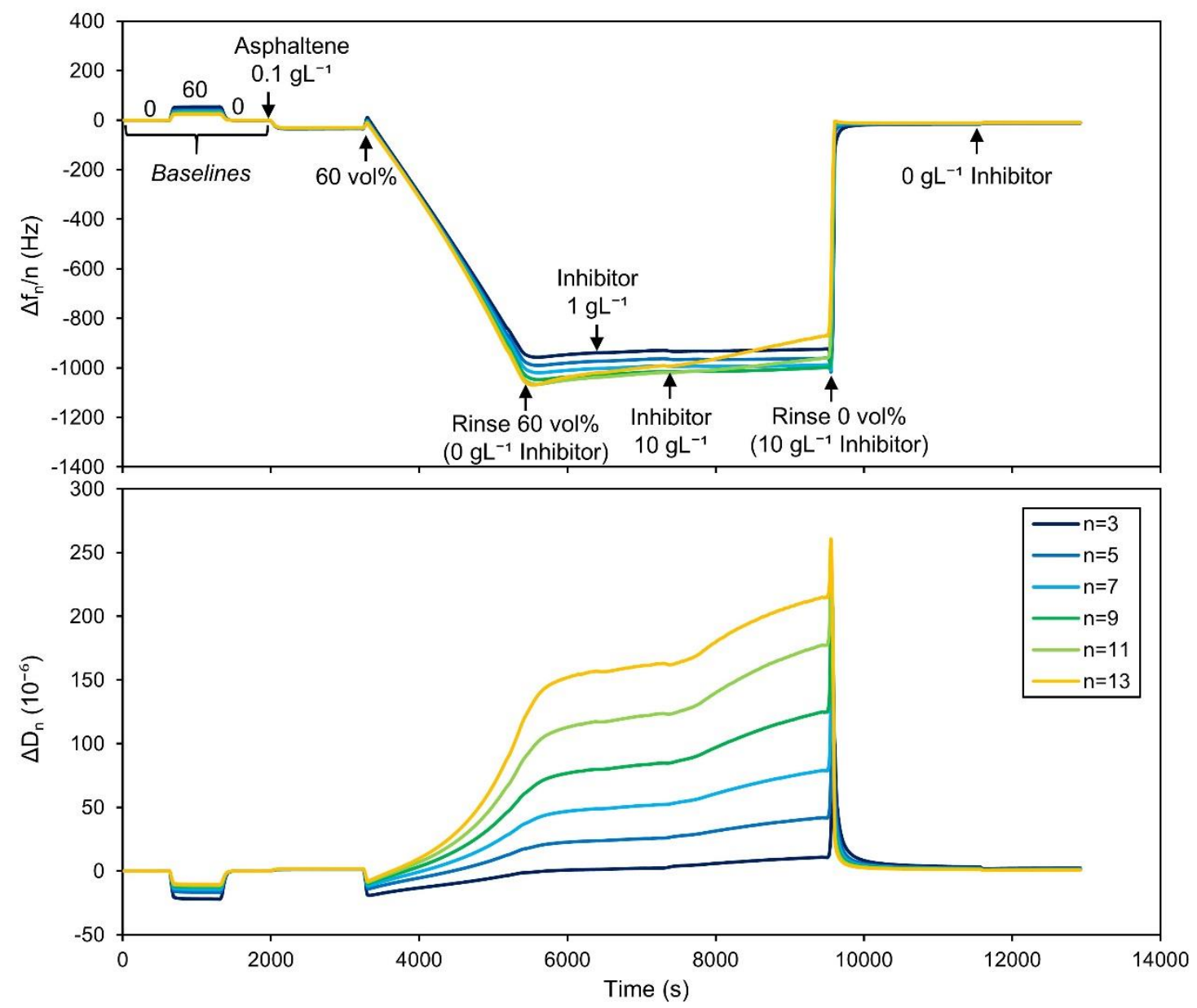

Figure 11. Use of Inhibitor A to remove pre-deposited asphaltene films in heptane-toluene, QCM-D frequency (top) and dissipation (bottom), $20^{\circ} \mathrm{C}, 20 \mu \mathrm{Ls}^{-1}$ flow rate. Rinsing with Inhibitor A, initially in 60 vol\% heptane and later in 0 vol\% heptane. 
(a)

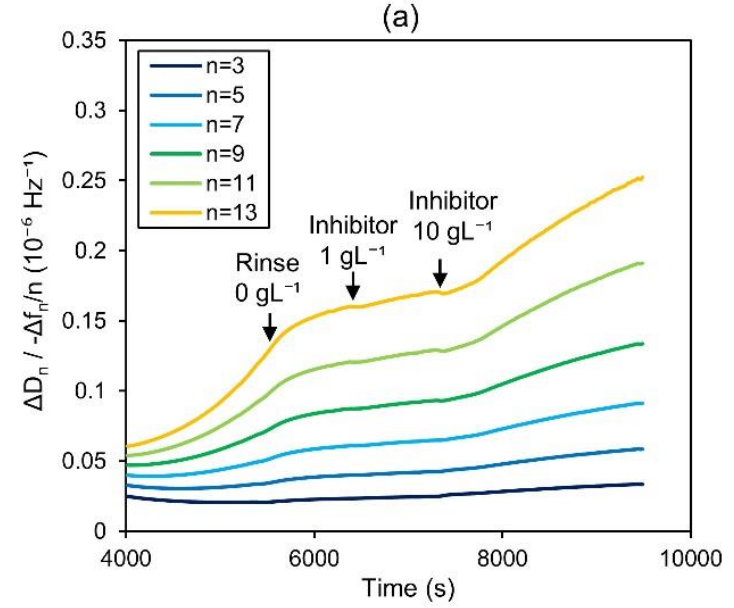

(b)

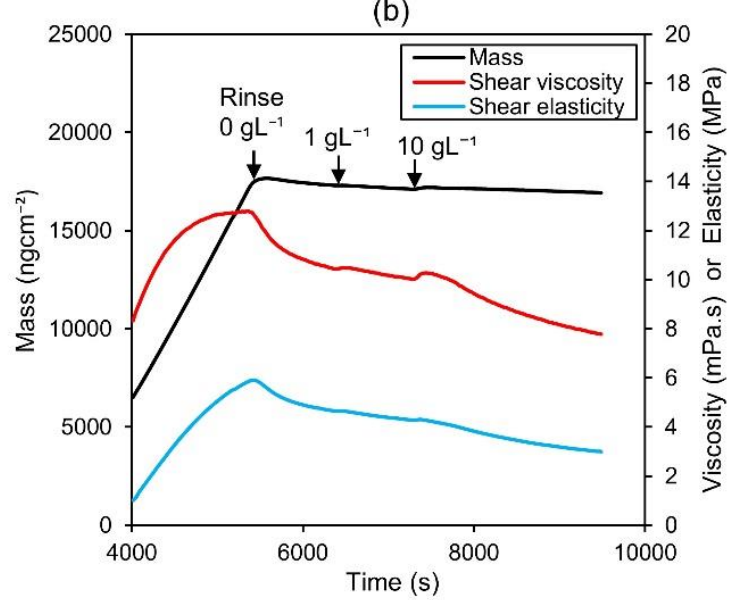

Figure 12. Analysis of asphaltene deposit rinsing in 60 vol\% heptane with Inhibitor A (data shown in Fig 11), (a) relative dissipation vs. time and (b) Voigt viscoelastic fitting of data 
(a)

(b)

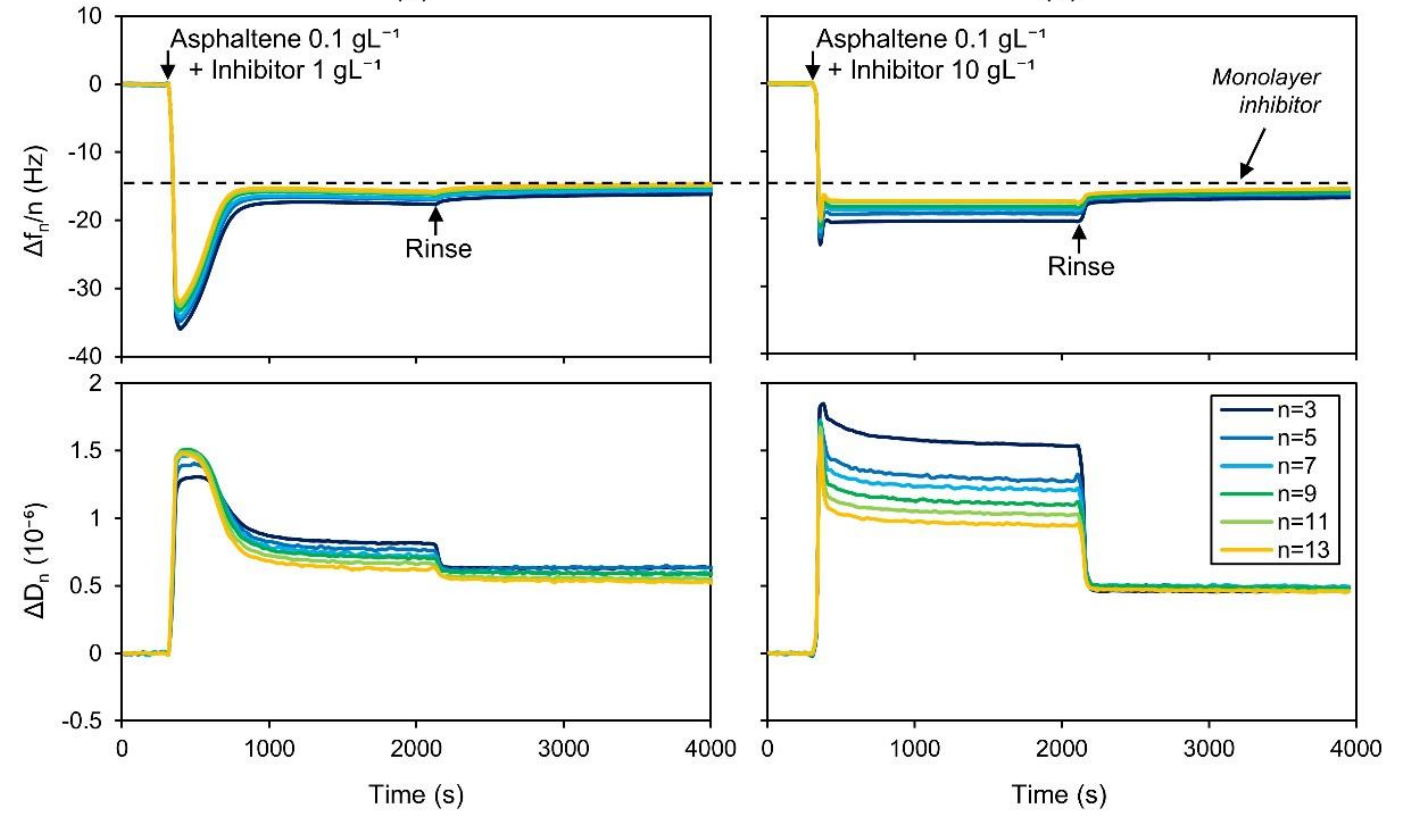

(c)

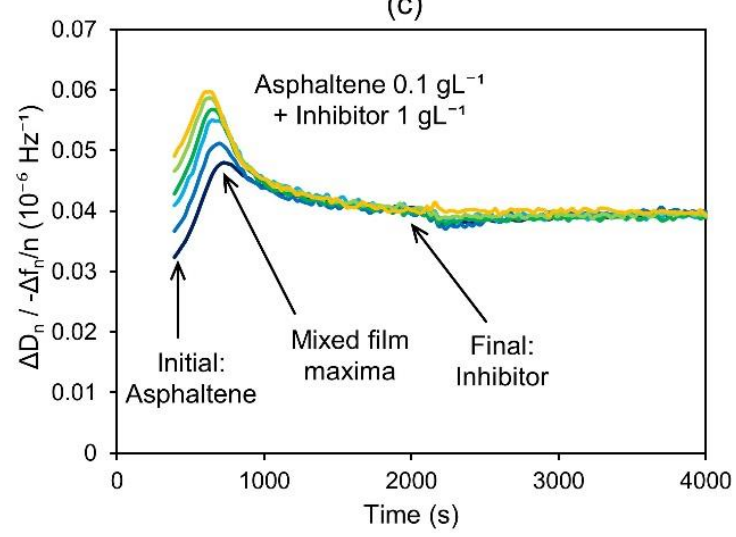

(d)

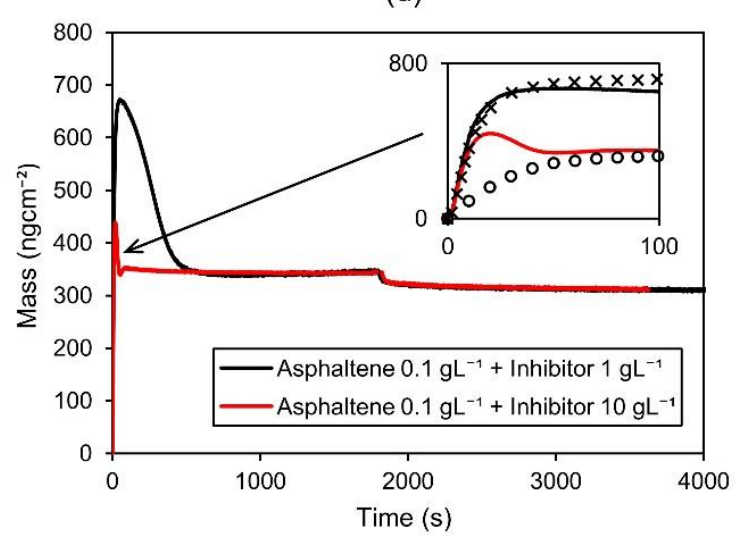

Figure 13. Deposition from pre-mixed asphaltene-Inhibitor A solutions in toluene, QCM-D frequency and dissipation shifts for asphaltene with (a) 1 and (b) $10 \mathrm{gL}^{-1}$ inhibitor, (c) relative dissipation showing changing film properties with time and (d) Voigt mass vs. time with inset showing early stage of the deposition. Adsorption of $0.1 \mathrm{gL}^{-1}$ asphaltene only (crosses) and $10 \mathrm{gL}^{-1}$ inhibitor only (open circles) are also indicated on inset to $(d)$. 
(a)

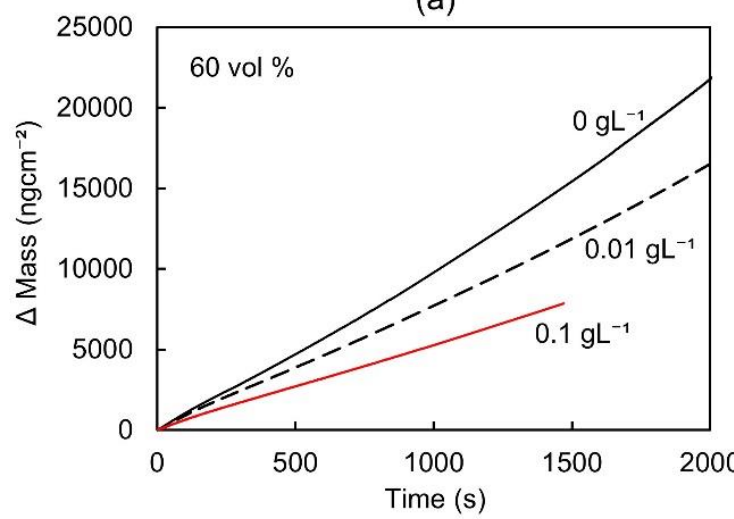

(c)

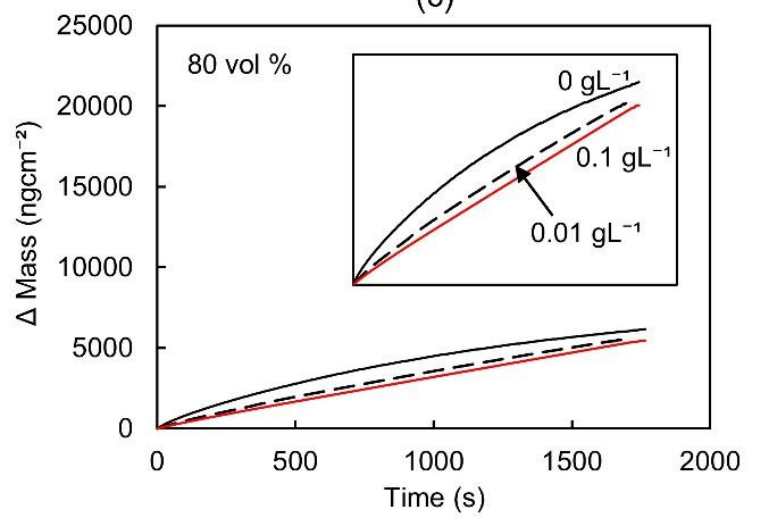

(b)

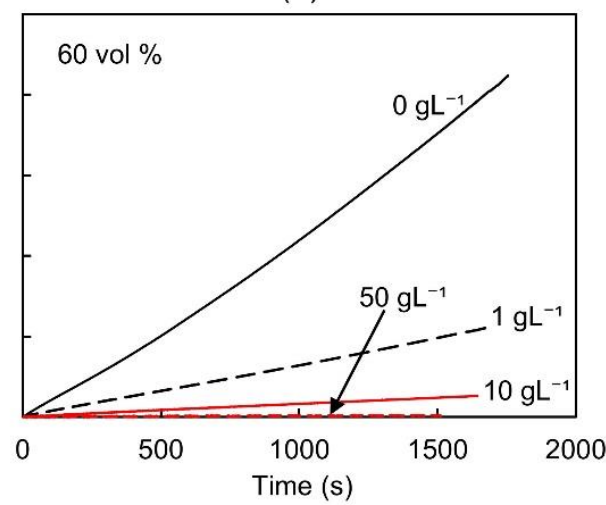

(d)

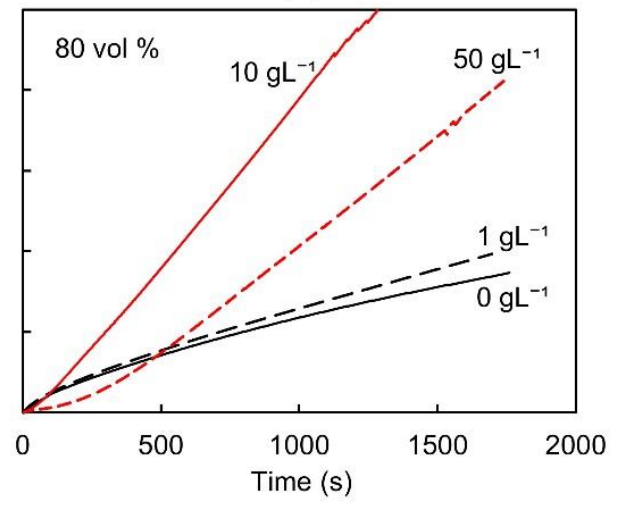

Figure 14. Deposition from pre-mixed asphaltene-Inhibitor A solutions in heptane-toluene, (a) low (0, $\left.0.01,0.1 \mathrm{gL}^{-1}\right)$ and (b) high (0,1, 10, $\left.50 \mathrm{gL}^{-1}\right)$ inhibitor concentrations in 60 vol\% heptane, (c) low and (d) high inhibitor concentrations in 80 vol\% heptane

(a)

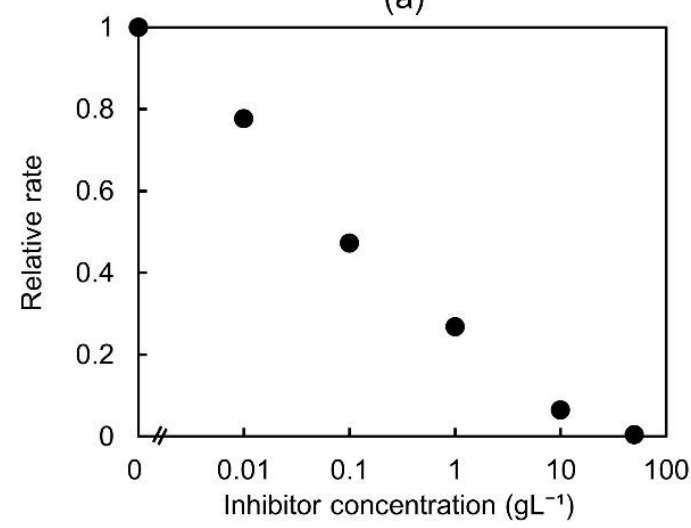

(b)

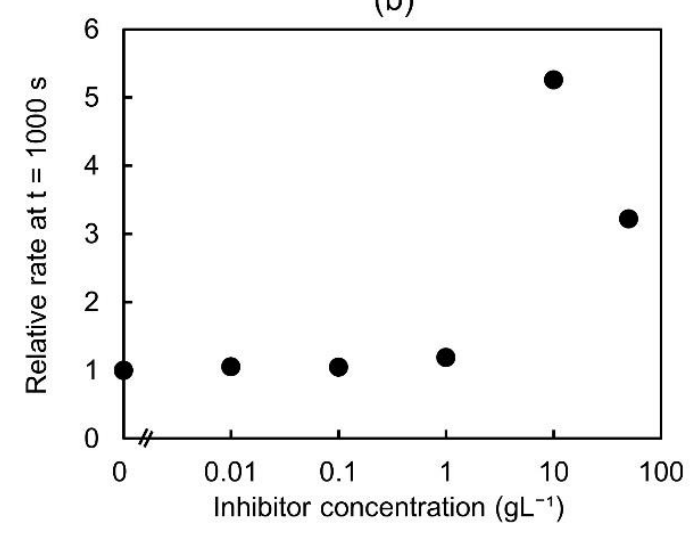

Figure 15. Effect of Inhibitor A concentration on relative deposition rates from (a) 60 and (b) 80 vol\% heptane, relative rate is respective to experiments without inhibitor 

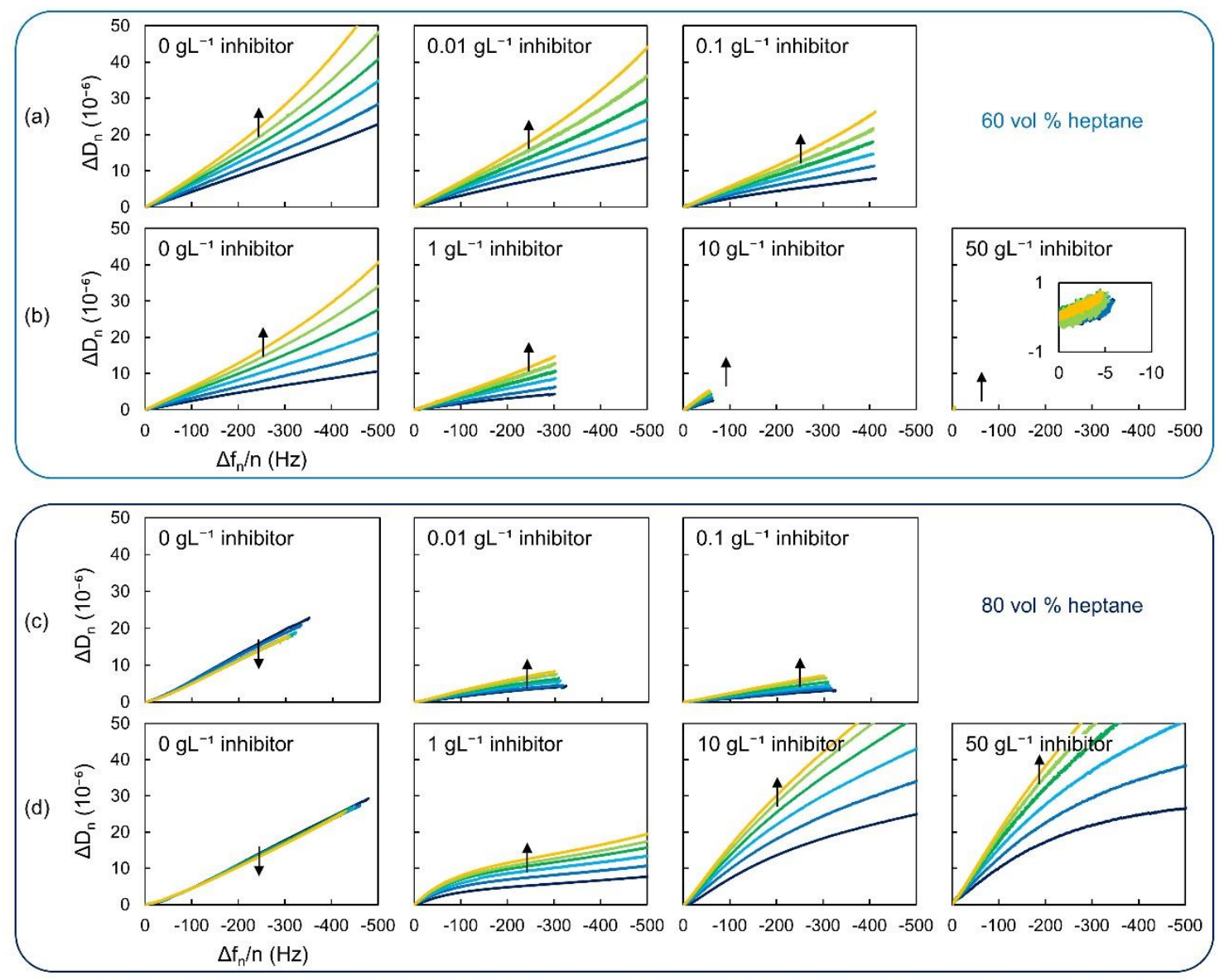

Figure 16. Graphs showing $\Delta \mathrm{D}_{\mathrm{n}}$ vs. $\Delta \mathrm{f}_{\mathrm{n}} / \mathrm{n}$ during deposition of asphaltene from heptane-toluene with inhibitor, (a) low and (b) high inhibitor concentrations in 60 vol\% heptane, (c) low and (d) high inhibitor concentrations in 80 vol\% heptane, arrows indicate direction of increasing overtone number $(n=3,5$, $7,9,11$ and 13) 

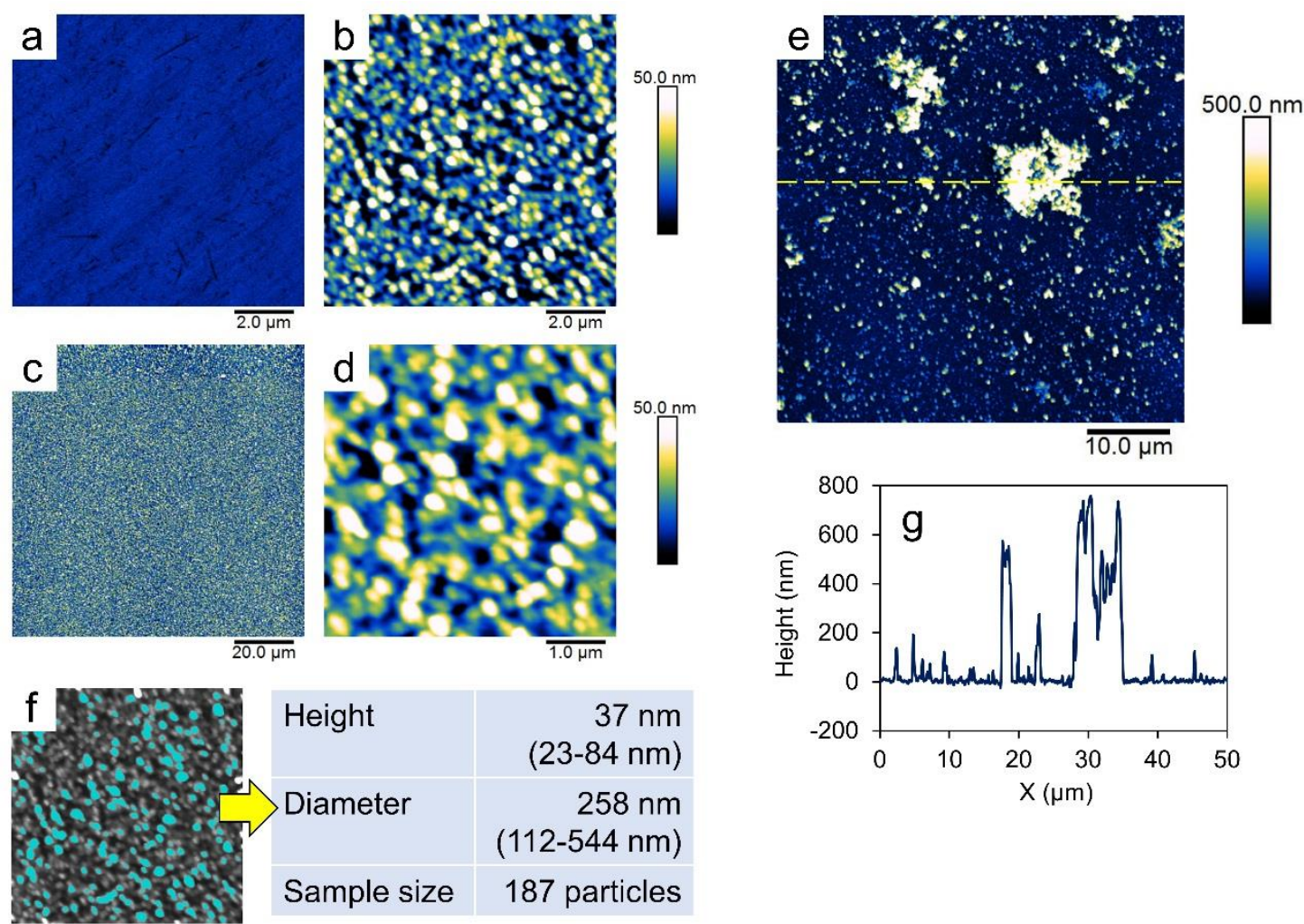

Figure 17. AFM of deposits formed with and without inhibitor in 80 vol\% heptane; height images of (a) clean gold surface, (b,c,d) $0.1 \mathrm{gL}^{-1}$ asphaltene with $10 \mathrm{gL}^{-1}$ inhibitor and (e) $0.1 \mathrm{gL}^{-1}$ asphaltene without inhibitor; (f) particle size analysis of deposit with inhibitor from image $b$ and $(g)$ line profile from image e 


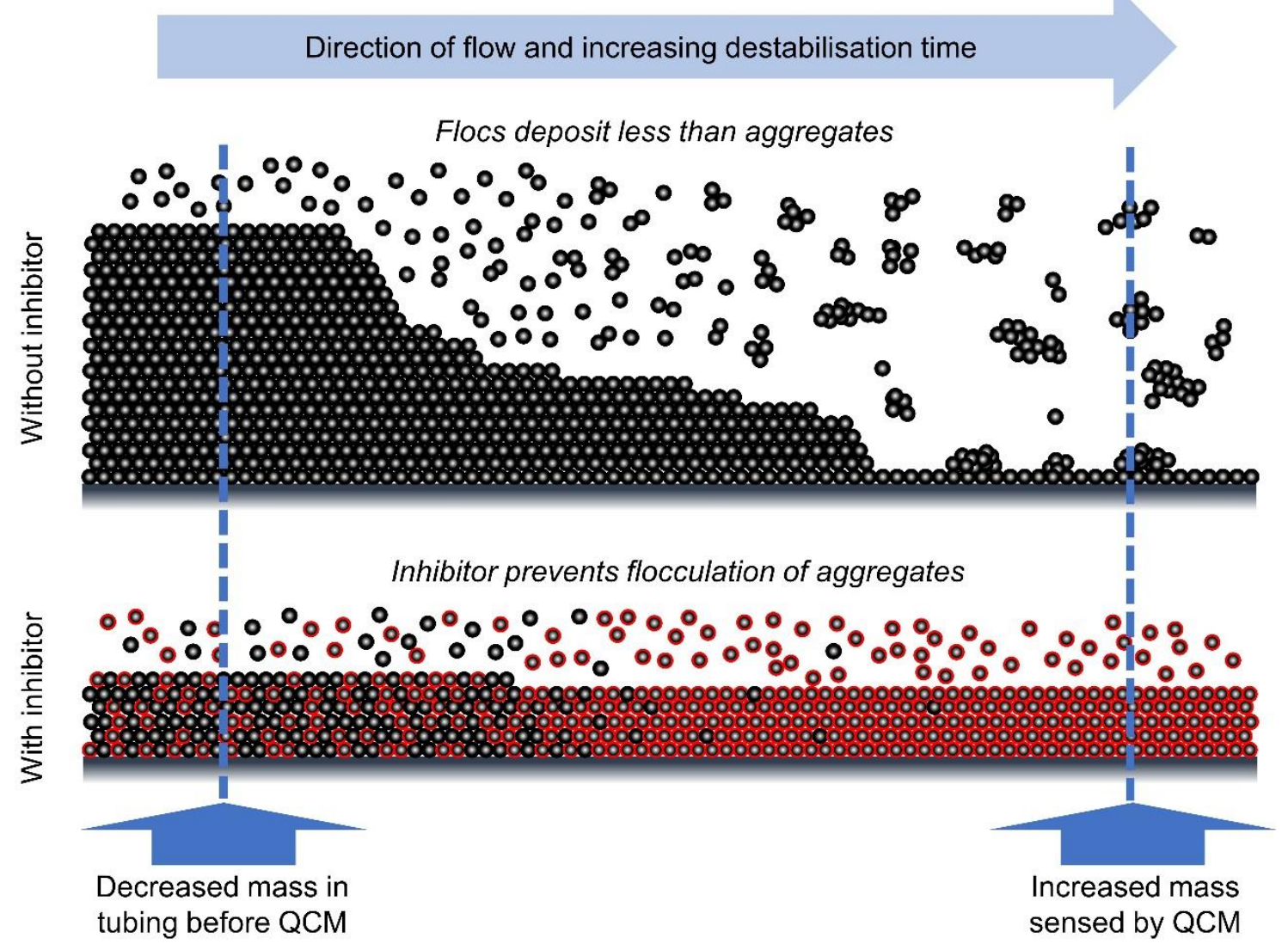

Figure 18. Illustration showing suggested impact of inhibitor on asphaltene deposition from 80 vol\% heptane. Asphaltene particles (grey) are coated by inhibitor (red) which acts as a dispersant and prevents formation of large flocculent aggregates 